\title{
Tribocorrosion Behavior of Calcium- and Phosphorous-Enriched Titanium Oxide Films and Study of Osteoblast Interactions for Dental Implants
}

\author{
S. A. Alves ${ }^{1,2} \cdot$ R. Bayón ${ }^{3} \cdot$ V. Saénz de Viteri ${ }^{3} \cdot$ M. P. Garcia ${ }^{4}$ A. Igartua ${ }^{3}$. \\ M. H. Fernandes ${ }^{4}$ L. A. Rocha ${ }^{1,5,6}$
}

Received: 17 March 2015/Revised: 10 July 2015/ Accepted: 29 July 2015/Published online: 6 August 2015

(C) Springer International Publishing AG 2015

\begin{abstract}
Titanium (Ti) dental implants are frequently exposed simultaneously to a corrosive environment and cyclic micromovements at implant/abutment and implant/ bone interfaces, becoming part of a tribocorrosion system. Thus, wear debris and corrosion products/ions can be released to peri-implant tissues and induce inflammatory reactions leading to implant failure. Moreover, the poor osseointegration is also one of the main problems affecting dental implants lifetime. Surface modification strategies have been proposed to design novel Ti oxide-based multifunctional surfaces that are able to simultaneously improve cellular functions and provide enhanced tribocorrosion resistance. Hence, the main objective of this work was the synthesis of Calcium (Ca)- and Phosphorous (P)-enriched $\mathrm{Ti}$ oxide films aimed to display superior wear/corrosion performance and simultaneously, to enhance osteoblast-material interactions. Ca- and P-enriched films were synthesized by plasma electrolytic oxidation (PEO) and their characteristics were assessed by
\end{abstract}

S. A. Alves

sofiafonso@msn.com,

1 Center MicroElectroMechanical Systems (MEMS-UMinho), Universidade do Minho, Guimarães, Portugal

2 American Branch of the Institute of Biomaterials (IBTN/US), Tribocorrosion and Nanomedicine, Chicago, IL, USA

3 Fundación IK4-Tekniker, Eibar, Spain

4 Faculdade de Medicina Dentária da Universidade do Porto (FMDUP), Porto, Portugal

5 Universidade Estadual Paulista (UNESP), Faculdade de Ciências de Bauru, Bauru, Brazil

6 Brazilian Branch of the Institute of Biomaterials (IBTN/Br), Tribocorrosion and Nanomedicine, Bauru, SP, Brazil
Field emission scanning electron microscopy, profilometry, energy-dispersive X-ray spectroscopy, X-ray diffraction, and water contact angle measurements. PEO-treated samples were subjected to pin-on-disk reciprocating sliding tests in artificial saliva at $37{ }^{\circ} \mathrm{C}$. The viability of MG63 cells cultured on PEO-treated samples was investigated by MTT assay, and their adhesion ability by SEM and confocal laser scanning microscopy. The wear/corrosion behavior of Ti was improved after PEO treatments and the electrolyte composition appeared to play a crucial role both on its corrosion tendency and mechanical wear resistance. It is believed that this improvement is related to the higher rutile/anatase ratio exhibited by $\mathrm{Ca}$ - and $\mathrm{P}$-enriched surfaces. Osteoblasts were well spread on these surfaces displaying improved viability/proliferation compared to Ti.

Keywords Titanium - Plasma electrolytic oxidation . Oxide films · Tribocorrosion · Osteoblasts · Dental Implants

\section{Introduction}

Commercially pure titanium (cp-Ti) and its alloys are commonly used for dental implant applications owing to their good mechanical properties, excellent corrosion resistance in biological fluids as well their very low toxicity $[1,2]$. The high corrosion resistance of cp-Ti and its superior biocompatibility is related to the formation of a stable and tightly adherent protective titanium oxide film (1.5-10 nm thick) on its surface, like $\mathrm{TiO}_{2}$, under contact with the surrounding environment [1,3-8].

Despite dental implants have become a highly successful and routine treatment to replace tooth loss due to decay, trauma, or periodontal diseases, a significant number of 
failures have still been reported (1-20\%) [9-11]. Despite their attractive properties, $\mathrm{Ti}$ and its alloys generally exhibit poor wear resistance which is a concern [2-4]. As titanium-based materials readily gall, seize, and wear when brought into sliding contact with other materials [12], biomechanical factors are commonly associated with dental implants failure. When in vivo physiological conditions, mastication loads are distributed through the structural materials, part of the dental implant system, leading to cyclic micromovements at implant/abutment and implant/ bone interfaces. Simultaneously, these sliding contacting surfaces can be chemically attacked due to the peri-implant corrosive environment (e.g., human saliva and oral biofilms accumulated at the peri-implant areas) and become part of a tribocorrosion system. Under these conditions, the passive film existing on Ti surface might not be sufficiently stable to withstand the mechanical action and the corrosive media existing in its surroundings, and may be degraded simultaneously by wear and corrosion mechanisms, a process known as tribocorrosion [2, 13, 14]. Tribocorrosion results from interactions between chemical, mechanical, and electrochemical processes, which may cause an irreversible transformation on the materials [13, 15]. As a consequence of this complex process, the release of wear debris and corrosion products/ions to peri-implant tissues can occur [2, 16]. Olmedo et al. [17] have reported two novel cases of reactive lesions of the peri-implant mucosa associated with Ti dental implants where metal-like particles were histologically observed and might be attributed to a tribocorrosion process. Recently, efforts have been made aiming a better understanding on the tribocorrosive behavior of $\mathrm{Ti}$ dental implants once exposed to the aggressive oral environment in which agents such as bacterial biofilms, saliva, and food are present [2, 18-21]. Binon et al. [22] reported a direct correlation between the implant/abutment rotational misfit and abutment screw loosening. The presence of micro-sized gaps at implant/ abutment interface might lead to micro-leakage of oral fluids, microorganisms, and small debris to the internal connection of implant systems. These micro-gaps and retentive areas at dental implant interfaces are the most susceptible for bacterial colonization and biofilm formation, which can exert a strong influence on corrosion and wear processes with further inflammation of peri-implant soft and hard tissues. Degradation and inflammatory processes can contribute to the loss of mechanical integrity of metallic structures influencing the magnitude of micromovements between dental implant components, and furthermore, compromise the long-term health of peri-implant tissues [13, 20, 23-27]. Adverse biological reactions such as gingival swelling and erythema, mucosal pain, and lichenoid reactions can be induced by the metallic ions released during corrosion of dental alloys [28]. In accordance with Wang et al. [29], nano-sized or ultrafine $\mathrm{TiO}_{2}$ can cause genotoxicity and cytotoxicity in cultured human cells. The wear particles and corrosion products released from the metallic implant structures can induce to foreign body inflammatory responses with release of different cytokines, activation of macrophages, and consequent periprosthetic osteolysis and ultimately, the prosthesis failure [1, 27, 30-32].

The clinical long-term success of dental implants is also dependent on their early osseointegration $[6,33]$. The lack of bone formation around the biomaterial site after implantation is also one of the most frequent causes of dental implants failure [34], and so there is a growing interest in shortening the osseointegration period after implantation [35]. The osseointegration process is related to the early interactions between bone cells and implant surface [36]. Several researches have been carried out showing that implant surface features play a crucial role on this process [33, 37-39]. It is known that implant surface topography, morphology, and chemical composition have a critical influence on proliferation, differentiation, and osteoblastic extracellular matrix (ECM) expression $[16,36$, $40,41]$. These factors are crucial for protein adsorption and cell adhesion both in early cell-material interactions as well during later and more chronic phases of cell responses $[36,38,39,42]$. Furthermore, the tribocorrosion performance of metallic biomaterials depends also on the physical, mechanical, structural, and chemical properties of their surfaces [13]. Hence, it is of fundamental importance the use of appropriate surface modifications to enhance wear and corrosion resistance of dental implants, and simultaneously, improve the bone-implant contact. Several surface modification techniques such as Physical Vapor Deposition (PVD), Chemical Vapor Deposition (CVD), ion implantation, and surface oxidation have been applied upon materials in order to avoid surface damage and enhance surface properties of implants [43]. Moreover, chemical (e. g., CVD, sol-gel and alkaline treatments), thermal (e.g., thermal oxidation), and also electrochemical (e.g., electropolishing and anodic oxidation) methods have been induced on Ti-based materials in order to achieve an enhanced biological response and tissue integration [35, 44-50]. Plasma-sprayed hydroxyapatite (HA) coatings have been widely used to improve bioactivity of Ti materials aiming to enable a quicker healing process after implantation. However, these coatings have shown poor long-term performance associated to the poor adhesion of the coating to the substrate $[44,51]$.

Recently, Plasma Electrolytic Oxidation (PEO) became one of the most important techniques to produce porous and well-adhered ceramic-like films on Ti surfaces [43]. PEO is being particularly attractive for $\mathrm{Ti}$ surface treatments allowing the production of crystalline $\mathrm{TiO}_{2}$ films in 
which rutile and anatase phases can enhance wear and corrosion resistance of materials [4, 43, 52- 54]. Furthermore, this technique allows the incorporation of bioactive elements such as calcium $(\mathrm{Ca})$ and phosphorous $(\mathrm{P})$ into anodic films during the conversion of the metal surface into Ti oxide [1, 3, 43, 55-58]. Beyond a wide range of surface treatments that have been employed to $\mathrm{Ti}$ and its alloys, PEO technique has been weakly explored. There is an emergent need in the development of new bio-multifunctional implant surfaces enhancing osseointegration and displaying an adequate corrosion/wear performance.

The main objective of this study was the synthesis of Calcium (Ca)- and Phosphorous (P)-enriched Ti oxide films aimed to display superior wear/corrosion performance and simultaneously, to enhance osteoblast-material interactions. The anodic films were synthesized by Plasma Electrolytic Oxidation (PEO). The influence of PEO process duration and electrolyte composition on topography, morphology, chemical composition, crystalline structure, and tribocorrosion behavior of the $\mathrm{Ca}$ - and $\mathrm{P}$-enriched films was investigated. Finally, their biological properties were assessed for osteoblastic cells viability/proliferation and adhesion ability.

\section{Materials and Methods}

\subsection{Synthesis of Ca- and P-Enriched Ti Oxide Films by PEO}

For this study, square samples of cp-Ti grade 2 (Goodfellow Cambridge Limited, England) with $10 \mathrm{~mm} \times 10 \mathrm{~mm}$ and $2 \mathrm{~mm}$ of thickness were the substrates used for PEO treatments. Prior to surface treatments, cp-Ti substrates were chemically etched in highly concentrated acid solution containing hydrofluoric acid $(\mathrm{HF})$, nitric acid $\left(\mathrm{HNO}_{3}\right)$ and distilled water $\left(\mathrm{H}_{2} \mathrm{O}\right)$ (1:1:1 proportion) for $3-5 \mathrm{~s}$, in order to remove the natural oxide layer present on their surfaces. After etching, specimens were ultrasonically cleaned in propanol (10 $\mathrm{min})$ and distilled water $(5 \mathrm{~min})$, and finally they were dried in warm air. In this study, the chemically etched cp-Ti samples were the substrates used for PEO treatments and they were named as cpTi_Reference.

For PEO treatments, a commercial Keronite PEO equipment was used (20 kW AC power supply, KERONITE, KT 20-50, United Kingdom) with cp-Ti_Reference samples working as the anode and a stainless steel mesh incorporated into an electrochemical cell of 50 liters capacity, served as the cathode. PEO treatment was performed in two different aqueous electrolyte solutions: (1) a commercial electrolyte (CE) provided from Keronite (Keronite Electrolyte 1003-01 for titanium) composed of
0.1-1\% sodium fluoride $(\mathrm{NaF})$ and other elements such as $\mathrm{Ca}$ and $\mathrm{P}$; (2) a $\mathrm{Ca} / \mathrm{P}$-based electrolyte $(\mathrm{C} \beta)$ composed of $0.35 \mathrm{M}$ of calcium acetate (calcium acetate hydrate, Scharlab, Spain) and $0.02 \mathrm{M}$ of $\beta$-glycerol phosphate $(\beta$ glycerol phosphate disodium salt pentahydrate, Scharlab, Spain). In our previous work [59], the influence of PEO current density on anodic films features was investigated by PEO treatments carried out at 3 and $8 \mathrm{~A} / \mathrm{dm}^{2}$ for $10 \mathrm{~min}$ in $\mathrm{CE}$ electrolyte. In the present investigation, we aim to study the influence of PEO processing time and electrolyte composition on the characteristics of anodic films. For that purpose, PEO treatments were carried out at $8 \mathrm{~A} / \mathrm{dm}^{2}$ for 5 and $10 \mathrm{~min}$, in CE electrolyte, and at $8 \mathrm{~A} / \mathrm{dm}^{2}$ for $5 \mathrm{~min}$ in $\mathrm{C} \beta$ electrolyte. An additional PEO treatment was carried out in $\mathrm{C} \beta$ electrolyte at $25 \mathrm{~A} / \mathrm{dm}^{2}$ for $10 \mathrm{~min}$ in order to evaluate the influence of harsher anodizing conditions on the anodic films features. In Table 1, the different groups of samples studied in this work are identified, in accordance with the parameters used for PEO treatments. All the experiments were performed under stirring and the electrolyte temperature was maintained below $40^{\circ} \mathrm{C}$. The total surface area of substrates exposed to electrolyte in each PEO process was approximately $4 \mathrm{~cm}^{2}$ (four samples of $1 \mathrm{~cm}^{2}$ were anodized simultaneously per process). After PEO treatments, the samples were immediately rinsed with distilled water and ultrasonically cleaned in propanol (10 $\mathrm{min})$ and distilled water (5 min). Finally, they were dried in warm air.

\subsection{Surface Characterization}

The surface morphology of cp-Ti_Reference and PEOtreated samples was analyzed by Field Emission Scanning Electron Microscopy (FESEM, Zeiss GEMINI ${ }^{\circledR}$, Zeiss, Jena, Germany). To observe the cross section of the anodic films, the samples were prepared by a conventional metallographic technique. Briefly, the samples were vertically embedded into a conductive resin, wet ground with silicon carbide (SiC) abrasive paper (120-1200\#), and then polished with $2 \mu \mathrm{m}$ diamond paste. The elemental composition of the surfaces was also investigated by Energy-Dispersive Spectrometer (EDS) incorporated into the FESEM system.

The average roughness $\left(R_{\mathrm{a}}\right)$ of cp-Ti_Reference and PEO-treated surfaces was accessed by a profilometer (Perthometer M2, Mahr, Nikon Instruments Inc., Melville, USA). The thickness of the anodic films was evaluated using a Dual-Scope probe (Fisher, Fischer Technology, Inc., Windsor, USA).

X-ray diffraction (XRD) analysis was carried out to evaluate the crystalline structure of the anodic films. The XRD patterns of the films were obtained by a diffractometer (X'Pert ${ }^{3}$, PANalytical, The Netherlands) equipped with a $\mathrm{Cu} \mathrm{K} \alpha$ radiation source in the $2 \theta=5^{\circ}-70^{\circ}$ range. 
Table 1 PEO processing parameters used for $\mathrm{cp}-\mathrm{Ti}$ surface treatments

\begin{tabular}{llll}
\hline Group of samples & Current density $\left(\mathrm{A} / \mathrm{dm}^{2}\right)$ & Process duration $(\mathrm{min})$ & Electrolyte \\
\hline PEO_CE, 8,5 & 8 & 5 & $\mathrm{CE}$ \\
PEO_CE, 8,10 & 8 & 10 & $\mathrm{CE}$ \\
PEO_C $\beta, 8,5$ & 8 & 5 & $\mathrm{C} \beta$ \\
PEO_C $\beta, 25,10$ & 25 & 10 & $\mathrm{C} \beta$ \\
\hline
\end{tabular}

For the informatic processing and phase identification, the software PANalytical X'pert HighScore (PANalytical, The Netherlands) was employed in combination with PDF2 (ICDD) database.

The water contact angles (WCA) were measured by sessile drop technique using a contact angle measurement apparatus (OCA 15 plus, Dataphysics, Germany) equipped with a camera imaging system. The measurements were performed at room temperature using distilled water. A $2 \mu \mathrm{l}$ droplet of distilled water was suspended from the tip of a microliter syringe. The syringe tip was directed toward the sample until the droplet be in contact with its surface. Pictures were collected from the camera and the contact angle between the droplet and the surface was calculated from a magnified image, by use of appropriate software.

\subsection{Tribocorrosion Experiments}

A tribo-electrochemical approach was used to study the tribocorrosion behavior of cp-Ti_Reference and PEOtreated samples. Samples were fixed in a Teflon electrochemical cell with the desired surface facing upwards with an exposed area to the test solution of $1 \mathrm{~cm}^{2}$. The electrochemical cell was mounted on a pin-on-disk tribometer (UMT-3-CETR, Bruker, USA) with a reciprocating sliding configuration and an alumina ball ( $\varnothing 10 \mathrm{~mm})$ was selected as the counter body material because of its high wear resistance, chemical inertness, and electrical insulating properties [2]. For tribocorrosion experiments, a threeelectrode setup was used where cp-Ti_Reference and PEOtreated samples were used as the working electrode, a platinum $(\mathrm{Pt})$ wire was the counter electrode, and a silver/ silver chloride electrode ( $\mathrm{Ag} / \mathrm{AgCl}, 0.207 \mathrm{~V} v s$. SHE) was used as the reference electrode. The tribocorrosion behavior was investigated by of Open Circuit Potential (OCP) and Coefficient of Friction (COF) measurements. The OCP was monitored before, during, and after reciprocating sliding tests. Once the stabilization of the OCP was achieved, sliding tests were started. The sliding tests were performed at a normal load of $2 \mathrm{~N}$, a sliding frequency of $2 \mathrm{~Hz}$, and a linear displacement amplitude of $3 \mathrm{~mm}$ during $720 \mathrm{~s}$. After reciprocating sliding, the OCP was recorded for $1800 \mathrm{~s}$. The electrochemical measurements were carried out with the help of a potentiostat (Autolab, Eco Chemie PGSTAT30, Metrohm Autolab,
Utrecht, The Netherlands) coupled to specific software for monitoring of the electrochemical data. During the sliding process, COF values were recorded by of UMT-3 software.

For all tribocorrosion tests, the samples were immersed in artificial saliva (AS, Fusayama) with chemical composition described elsewhere [60], at $37{ }^{\circ} \mathrm{C}$. This electrolyte was chosen once on one side, it has been generally used in previous research works $[2,18,61,62,63]$ but also because the electrochemical behavior of metallic materials in Fusayama's saliva, its similar to the one observed in human saliva [64]. It is aimed to simulate the highly corrosive oral cavity environment with $\mathrm{Cl}^{-}, \mathrm{F}$, and $\mathrm{H}^{+}$ions playing a significant role on corrosion of dental implant materials [20].

After tribocorrosion assays, all the samples were ultrasonically cleaned with propanol $(10 \mathrm{~min})$ and distilled water $(5 \mathrm{~min})$. To guarantee the reproducibility of the results, the minimum of three samples for each group was tested.

After tribocorrosion tests, all the wear tracks were deeply analyzed. The morphology of the wear tracks was observed by FESEM. Furthermore, the topography and morphology of the wear scars were also measured by of confocal microscopy (Confocal Microscope Nikon Eclipse ME600, Canada) and the volume of the removed material due to tribocorrosion action (wear volume) was calculated. For wear volume measurements, a custom-developed software for confocal microscopy images analysis was used.

\subsection{Osteoblastic Cell Response}

The human osteosarcoma cell line MG63 (ATCC) was used for cell-material interactions studies. MG63 osteoblastic cells were cultured in standard culture plates in $\alpha$-Minimum Essential Medium ( $\alpha$-MEM, Gibco, USA) containing $10 \%$ of fetal bovine serum (FBS, Gibco, USA), penicillin, and streptomycin (100 IU/ml and $100 \mu \mathrm{g} / \mathrm{ml}$, Gibco, USA), $2.5 \mu \mathrm{g} / \mathrm{ml}$ amphotericin B (Gibco, USA) and $50 \mu \mathrm{g} / \mathrm{ml}$ ascorbic acid (Sigma-Aldrich, USA). At approximately $80 \%$ confluence, adherent cells were enzymatically detached from the bottom of the culture plate by of a solution of $0.05 \%$ trypsin and $0.25 \%$ EDTA. After the detachment, cells were counted in a hematocytometer (Celltac, Nihon KohdenMEK-5103 K, Japan) in order to produce a cell suspension with the desirable density of cells. 
Prior to cell seeding on materials surface, the samples were sterilized by autoclaving at $120{ }^{\circ} \mathrm{C}$ during $120 \mathrm{~min}$. After sterilization, the specimens were placed into standard 24-well culture plates (Orange Scientific, Belgium). The cells were seeded on the wells of the standard culture plates (control culture) and on the surface of cp-Ti_Reference and PEO-treated samples, at a density of $2 \times 10^{4} \mathrm{cell} / \mathrm{cm}^{2}$. After seeding, the cultures were maintained in a $5 \% \mathrm{CO}_{2}$ humidified atmosphere at $37{ }^{\circ} \mathrm{C}$. The culture medium was changed twice a week.

The control and colonized materials were observed by SEM (FEI Quanta 400 FEG scanning electron microscope equipped with EDS microanalysis capability, EDAX Genesis X4 M, USA) and Confocal Laser Scanning Microscopy (CLSM, Leica Microsystems, SP2 AOBS SE, Germany), and were also evaluated for cell viability/ proliferation.

\subsubsection{SEM Analysis}

After 1, 3, and 7 days of culture, the control and cultured materials, were washed in phosphate-buffered saline (PBS) and fixed $(1.5 \%$ glutaraldehyde in $0.14 \mathrm{M}$ sodium cacodylate buffer, $\mathrm{pH} 7.3,10 \mathrm{~min})$. Then the cells were dehydrated in graded alcohols (70, 80, 90 and $100 \%)$ for 10 min each. To simulate the critical point drying, solutions of hexamethyldisilazane (HMDS, Sigma-Aldrich, USA) in alcohol $(50,60,70,90$, and $100 \%)$ were progressively added to materials, during $10 \mathrm{~min}$ each. The materials were sputter-coated with gold and analyzed by SEM.

\subsubsection{CLSM Analysis}

For CLSM assessment, the control and cultured materials were labeled for actin filaments (F-actin) of cytoskeleton and nucleus. At 1, 3, and 7 days of culture, MG63 cells were washed in PBS and fixed $3.7 \%$ methanol free formaldehyde in PBS, $15 \mathrm{~min}$ ). Cultured materials were maintained in PBS solution at $4{ }^{\circ} \mathrm{C}$ until labeling. For labeling, cells were permeabilized with $0.1 \%$ triton in PBS, for $5 \mathrm{~min}$. A solution of $10 \mathrm{mg} / \mathrm{ml}$ of BSA with $1 \mu \mathrm{g} /$ $\mathrm{ml}$ RNAse in PBS was added and kept in incubation for 1 h. Following, a solution of $5 \mathrm{U} / \mathrm{ml}$ Alexa Fluor ${ }^{\mathbb{B}} 488$ Phalloidin (Invitrogen, Barcelona, Spain) was added and cells were incubated for $20 \mathrm{~min}$ in the dark. Alexa Fluor ${ }^{\circledR}$ 488-Phalloidin allows the fluorescence of the cytoskeleton through the binding of phalloidin to F-actin [65]. Afterwards, cells were washed with PBS, and then a solution of propidium iodide $(10 \mu \mathrm{g} / \mathrm{ml}$ in PBS; SigmaAldrich, USA) was added. Propidium iodide binds to DNA allowing its fluorescence [66]. After this, cells were incubated for $10 \mathrm{~min}$ in the dark, at room temperature. Cells were washed with PBS, and maintained in a mounting medium $(20 \mathrm{mM}$ tris with $\mathrm{pH} 0.8,0.5 \% \mathrm{~N}$-propyl gallate and $90 \%$ glycerol) before CLSM observation.

\subsubsection{MTT Assay}

The cell viability/proliferation of the colonized materials was evaluated by measuring the mitochondrial dehydrogenase activity by MTT reduction assay. The MTT (3-(4,5dimethyl-2-thiazolyl)-2,5-diphenyl-2H-tetrazolium bromide) assay allows the appraisal of living and metabolically active cells by their reduction activity of the yellow MTT to the correspondent insoluble purple formazan product through mitochondrial dehydrogenase [55, 67, 68]. After 1,3 , and 7 days, the cultured materials were incubated with MTT $(0.5 \mathrm{mg} / \mathrm{ml})$ for $3 \mathrm{~h}$ at $37{ }^{\circ} \mathrm{C}$. After the incubation period, the formazan crystals were solubilized in dimethyl sulfoxide (DMSO). The absorbance (Abs) was measured at $K=550 \mathrm{~nm}$ on a microplate reader spectrometer (Synergy HT, Biotek, USA). Results are expressed as Abs/cm².

\subsection{Statistical Analysis}

Experimental data in this study were reported as mean \pm standard deviation (SD). All the measurements were performed at an average of 3-6 replicates. The data were statistically evaluated by Student's $t$ test with the statistical tool SigmaStat 3.5 (USA), with $p<0.05$ considered as being statistically significant.

\section{Results and Discussion}

\subsection{Surface Characterization}

The primary surface state of the substrates used for PEO treatments was achieved by chemical etching. This surface pre-treatment ensures equal initial surface conditions for all the samples allowing the growth of the anodic films under more controlled conditions. The etched cp-Ti surface (cpTi_Reference) shows a rough topography (Fig. 1a) evidencing the typical granular structure of cp-Ti. The $R_{\mathrm{a}}$ of cp-Ti_Reference samples was $0.63 \pm 0.03 \mu \mathrm{m}$ (Table 2).

The morphology of the anodized surfaces at different PEO conditions is shown in Fig. 1b-e. After anodic oxidation treatments, the surfaces presented porous structures, which are typical to obtain after PEO treatments [67]. Micropores are produced in the dielectric breakdown regime associated to high local temperatures, sparks production, and the vigorous release of oxygen and/or water vapor release at surface/electrolyte interface $[16,46,61]$.

After PEO treatments carried out for 5 and $10 \mathrm{~min}$, the anodic films revealed a porous structure, however, with 


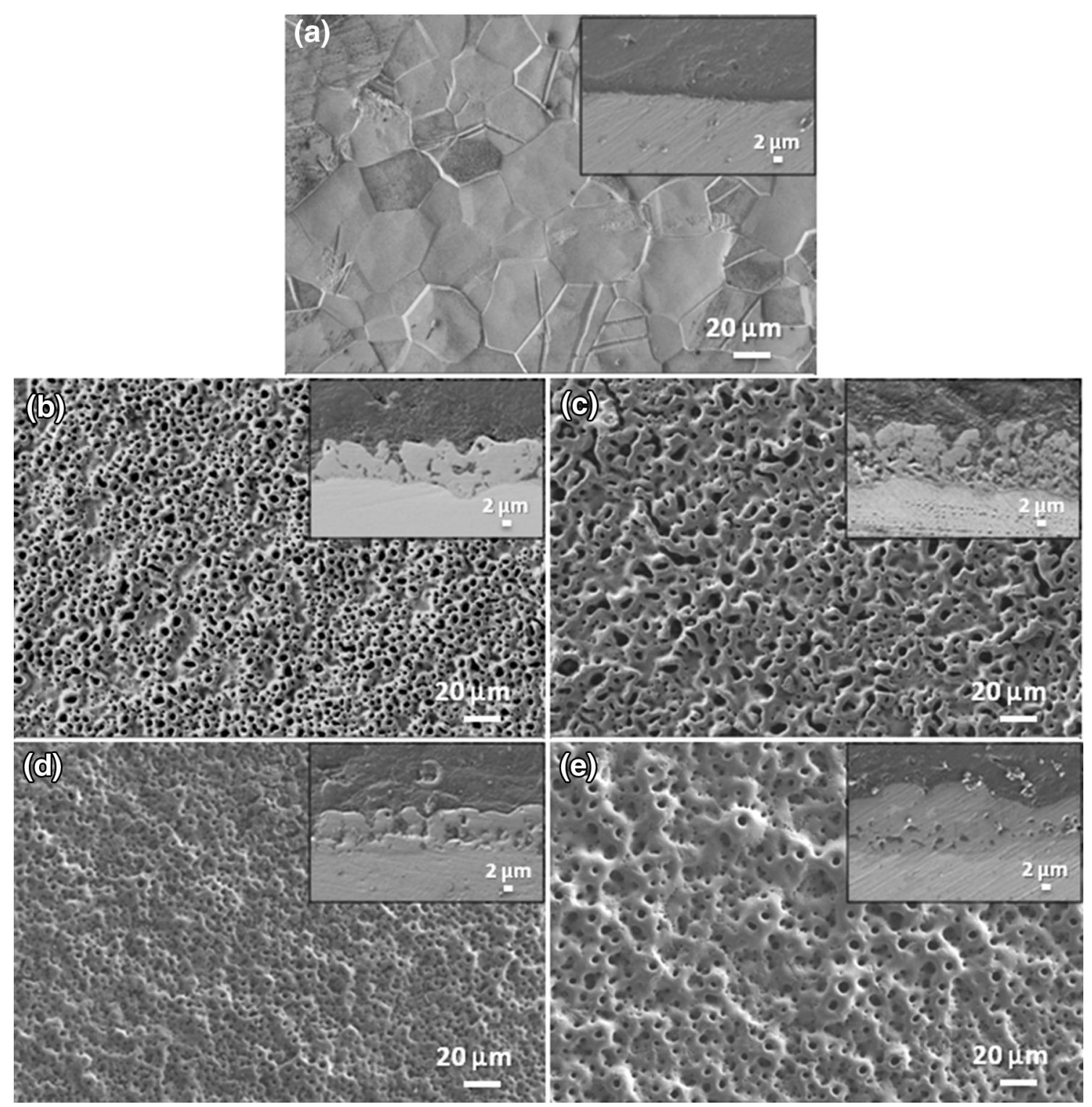

Fig. 1 FESEM micrographs of a cp-Ti_Reference, b PEO_CE,8,5, c PEO_CE, 8,10 , d PEO_C $\beta, 8,5$, and e PEO_C $\beta, 25,10$ samples. The SEM micrograph representative of the polished cross section of each

distinct pore size and morphology (Fig. 1b, c). Shorter PEO treatments accounted for oxide films with rounder and smaller pores (up to $6 \mu \mathrm{m}$ diameter), when compared to longer processing treatments after which large-sized pores up to $12 \mu \mathrm{m}$ diameter were formed. PEO_CE, 8,10 samples displayed pores with an elongated shape, which can reach up to $20 \mu \mathrm{m}$ length, probably resulting from interconnections between them [55, 69]. Cheng et al. [70] also investigated the effect of the oxidation time on surface features of anodic films containing silicon $(\mathrm{Si}), \mathrm{Ca}$, and $\mathrm{Na}$, and concluded that the pore size is in direct proportion to PEO time, which is in accordance with the results obtained in the present study. There are no significant changes in the different sample is shown in the right upper corner of the correspondent SEM picture

$\mathrm{R}_{\mathrm{a}}$ values measured for PEO-treated samples at different durations (Table 2). The thicknesses of the anodic films of PEO_CE, 8,5 and PEO_CE, 8,10 samples are $11.34 \pm 0.56$ and $15.74 \pm 0.26 \mu \mathrm{m}$.

In the present study, the influence of the electrolyte composition on pore size and morphology of the anodic films was also investigated. Both porous structures of PEO_CE, 8,5 and PEO_C $\beta, 8,5$ samples (Fig. 1b, d) display round-shaped morphology; however, the pores are smaller on those samples anodized in the $\mathrm{C} \beta$ electrolyte (up to $3 \mu \mathrm{m}$ diameter) when compared to those on samples treated in $\mathrm{CE}$ electrolyte (up to $6 \mu \mathrm{m}$ diameter). Some previous studies have shown that the pore size depends on the 
Table $2 \mathrm{R}_{\mathrm{a}}$ values and standard deviation (SD) of cp-Ti_Reference and PEO-treated samples and average thickness values of the anodic films grown at different $\mathrm{PEO}$ processing conditions

\begin{tabular}{lll}
\hline Group of samples & $\mathrm{R}_{\mathrm{a}}(\mu \mathrm{m} \pm \mathrm{SD})$ & Thickness $(\mu \mathrm{m} \pm \mathrm{SD})$ \\
\hline cp-Ti_Reference & $0.63 \pm 0.03$ & - \\
PEO_CE, 8,5 & $1.05 \pm 0.02^{*}$ & $11.34 \pm 0.56$ \\
PEO_CE, 8,10 & $1.19 \pm 0.02^{*}$ & $15.74 \pm 0.26^{\#}$ \\
PEO_C $\beta, 8,5$ & $1.10 \pm 0.06^{*}$ & $6.74 \pm 0.08^{\#}$ \\
PEO_C $\beta, 25,10$ & $1.75 \pm 0.14^{*}, \mathrm{x}$ & $20.27 \pm 0.59^{\mathrm{x}}$ \\
\hline
\end{tabular}

* Significantly different from cp-Ti_Reference, ${ }^{\mathrm{x}}$ Significantly different from PEO_C $\beta, 8,5,{ }^{\text {\# }}$ Significantly different from PEO_CE,8,5; $p<0.05$

composition of the electrolyte in which the specimens are anodized [71-73]. The differences between the pore sizes registered for samples anodized in different electrolytes can be associated with the quantity of spark discharges generated during each PEO process [72]. The anodic films produced in different electrolyte solutions are also characterized by different values of thickness. Significantly thicker anodic films are present on PEO_CE,8,5 when compared to PEO_C $\beta, 8,5$ samples, whose values are 11.34 $0.56 \mu \mathrm{m}$ and $6.740 .08 \mu \mathrm{m}$ (Table 2). Several researches have already reported that the thickness of the anodic oxide films strongly depends on the chemical composition of the electrolyte in which the specimens are anodized [52, 73]. As reported by Venkateswarlu et al. [74], the thickness values can be related with the electrolyte conductivity.

In the present study, anodic treatments were also performed in the $C \beta$ electrolyte at $25 \mathrm{~A} / \mathrm{dm}^{2}$ for $10 \mathrm{~min}$ (PEO_C $\beta, 25,10)$ in order to evaluate the surface characteristics of the films grown in this electrolyte under harsher anodizing conditions. After PEO treatments, a surface with a porous structure with round pores, well separated, larger (up to $6 \mu \mathrm{m}$ diameter), and more homogeneously distributed was produced (Fig. 1e) when compared to PEO_C $\beta, 8,5$ samples. Furthermore, the anodic films on PEO_C $\beta, 25,10$ samples are also significantly rougher and thicker (Table 2). Souza et al. [16] investigated the features of anodic films grown on Ti surfaces by anodization in a Ca- and P-based electrolyte. The authors also concluded that as higher the current density applied during the process, higher were the thickness and $\mathrm{R}_{\mathrm{a}}$ values of the created films. In our previous study [59], the influence of the PEO current density on the anodic film features was investigated. We concluded that PEO processes developed at higher current densities lead to the synthesis of anodic films with larger pores and significantly higher values of roughness and thickness.

In the present study, thicker anodic films were produced on those samples anodized under longer duration and higher current density, which can be associated to the larger pores existing on these samples. According to Kuromoto et al. [55], the presence of pores can favor the outgrowth of the film thickness, once pores are filled with electrolyte favoring the passage of the current. Furthermore, the differences on $R_{\mathrm{a}}$ values measured between cpTi_Reference and PEO-treated samples can be related with the differences on the surface morphology observed between them. It is reported that the presence of a threedimensional oxide structure consisting of numerous open pores leads to an increase in the surface roughness [75].

The polished cross sections of PEO-treated samples were observed by FESEM and the representative micrographs are depicted in the right upper corner of the correspondent FESEM images shown in Fig. 1. From inset images, the polished cross sections of the anodic films grown at different processing conditions are observed. Along their length, the anodic films display complex porous structures, with distinct porosity. From cross-sectional views, it seems that all the films are well adhered to cp-Ti substrates as it is expected to occur for films synthesized by PEO [52].

The chemical composition of cp-Ti_Reference and PEO-treated surfaces was investigated by EDS analysis and the correspondent spectra are shown in Fig. 2. It was found that the anodic films produced both in the $\mathrm{CE}$ and $\mathrm{C} \beta$ electrolytes are composed of $\mathrm{Ti}$, oxygen $(\mathrm{O})$, and $\mathrm{P}$ and $\mathrm{Ca}$ elements. PEO-treated samples in the $\mathrm{CE}$ electrolyte were also characterized by the presence of $\mathrm{Na}$. The $\mathrm{Ca} / \mathrm{P}$ ratios determined from EDS analysis were 0.14 for PEO_CE,8,5 and 0.41 for PEO_CE,8,10 samples. In the case of PEO_C $\beta, 8,5$ and PEO_C $\beta, 25,10$ samples, the content of $\mathrm{Ca}$ was significantly higher than in those specimens treated in the $\mathrm{CE}$ electrolyte, with $\mathrm{Ca} / \mathrm{P}$ ratios of 2.87 and 3.20, respectively,. $\mathrm{PEO}$ treatments in the $\mathrm{C} \beta$ electrolyte seem to favor significantly the incorporation of $\mathrm{Ca}$ into anodic films structure as can be deduced from $\mathrm{Ca} / \mathrm{P}$ ratios. These values are quite different than the one characteristic of HA, which is around 1.67 [76].

\subsection{Tribocorrosion Studies}

\subsubsection{Electrochemical Behavior and COF Measurements}

The evolution of the OCP for cp-Ti_Reference and PEOtreated samples is shown in Fig. 3a, before, during, and after reciprocating sliding tests. Before sliding, the OCP stabilized at different values, which reveals that the different groups of samples display a different tendency to corrosion in AS medium. Cp-Ti_Reference has the lowest OCP (close to $-0.01 \mathrm{~V}$ vs. $\mathrm{Ag} / \mathrm{AgCl}$ ), indicating higher corrosion tendency in AS. For all PEO-treated samples, a higher OCP was noticed as compared to cp-Ti_Reference, due to the presence of a protective anodic film. The same 


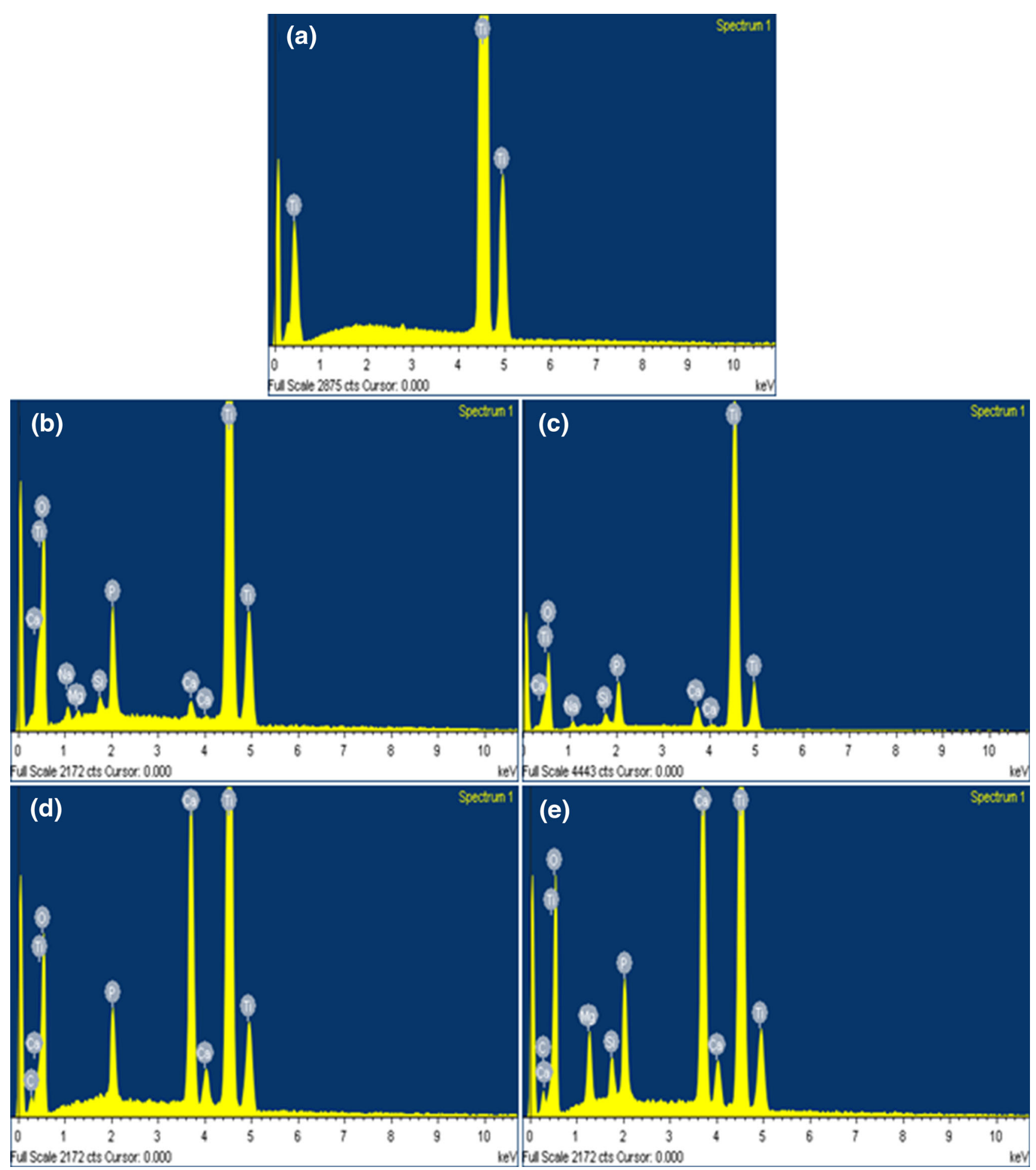

Fig. 2 EDS spectra of a cp-Ti_Reference, b PEO_CE,8,5, c PEO_CE,8,10, d PEO_C $\beta, 8,5$, and e PEO_C $\beta, 25,10$ samples

behavior was also reported by Oliveira et al. [63]. All PEOtreated samples in $\mathrm{CE}$ electrolyte displayed lower OCP values and so, higher corrosion tendency, when compared to samples treated in the $C \beta$ electrolyte.
As soon as mechanical solicitation started, the OCP of cp-Ti_Reference samples immediately dropped down from $-0.01 \mathrm{~V}$ to about $-0.82 \mathrm{~V}$ vs. $\mathrm{Ag} / \mathrm{AgCl}$ (Fig. 3a), revealing an increase on corrosion tendency. This indicates the fast 

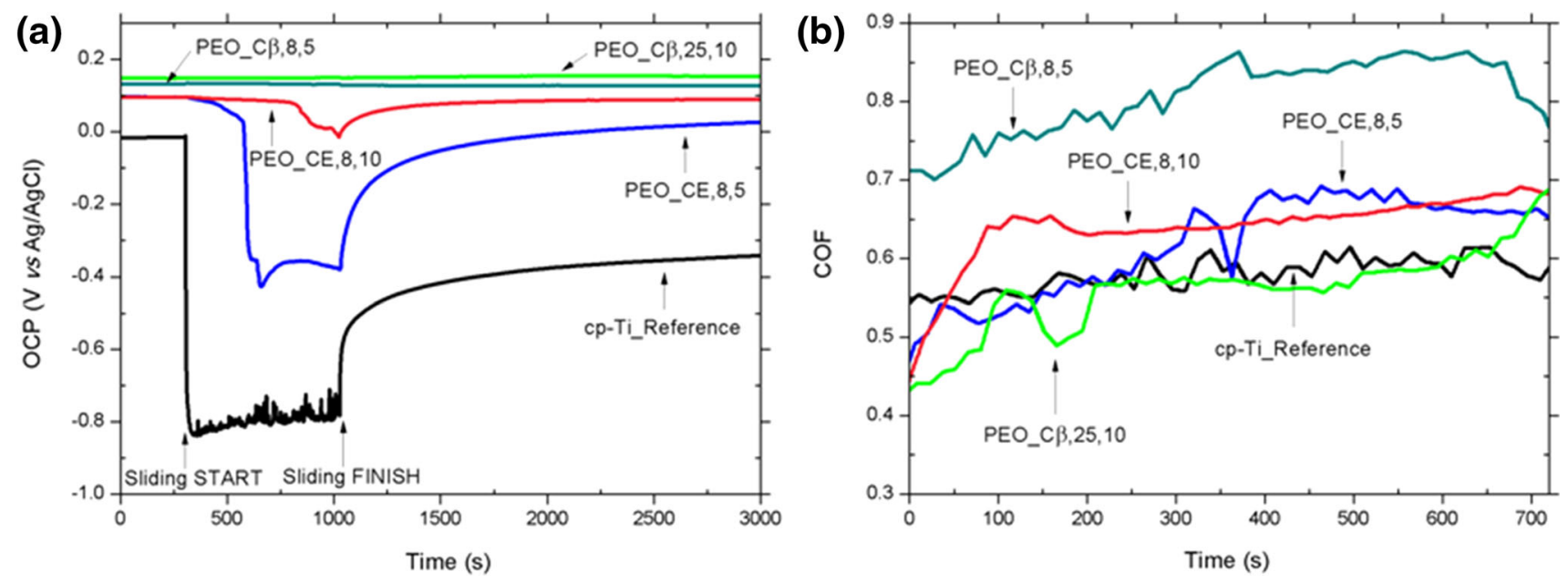

Fig. 3 Evolution of a OCP and b COF for cp-Ti_Reference, PEO_CE,8,5, PEO_CE,8,10, PEO_C $\beta, 8,5$, and PEO_C $\beta, 25,10$ samples immersed in AS (test conditions: $2 \mathrm{~N}, 3 \mathrm{~mm}, 2 \mathrm{~Hz}, 720 \mathrm{~s}$ )

disruption and/or removal of the natural oxide layer present on cp-Ti surface (depassivation), therefore exposing bare cp-Ti substrate to fresh electrolyte [2, 19, 30, 77]. For cpTi_Reference samples, the OCP values were maintained around $-0.80 \mathrm{~V}$ vs. $\mathrm{Ag} / \mathrm{AgCl}$ during the entire sliding test. After sliding, the OCP increased straight away to more noble values due to a re-growth of the passive film (repassivation) in the wear track [18, 30, 63]; however, it did not come back to the level before reciprocating sliding. This might indicate that the electrochemical state of the cpTi surface has been modified by the wear induced during mechanical solicitation, and therefore the newly formed passive film has dissimilar features when compared with the naturally one formed before mechanical loading [2]. This depassivation and repassivation behaviors of $\mathrm{cp}-\mathrm{Ti}$ in AS were also reported by Sousa et al. [18] They reported on the presence of a compact passive surface film on $\mathrm{Ti}$ immersed in AS free of fluorides or in the presence of up to $227 \mathrm{ppm} \mathrm{F}$. Additionally, they concluded that the corrosion and wear resistance of Ti oxide film were influenced by the $\mathrm{F}^{-}$concentration present in AS.

The PEO-treated samples are composed of Ti oxides with insulating properties. The measured OCP reflects the electrochemical behavior of the substrate in contact with the electrolyte impregnating the pores of the films. Thus, the OCP evolution during sliding might be related with local changes at cp-Ti substrate/electrolyte interface due to the progressive changes in film porosity, cracking, or local destruction of the oxide film as mechanical solicitation occurs. Once reciprocating sliding started, the OCP values for PEO_CE,8,5 samples suffered a gradual lowering, and after some min, the OCP values dropped abruptly till $\approx-0.42 \mathrm{~V}$ vs. $\mathrm{Ag} / \mathrm{AgCl}$ (Fig. 3a). This behavior might indicate that initially the anodic film was not destroyed and therefore, the cp-Ti substrate was protected against the corrosive environment. After few seconds, the OCP increased to noble values what can be associated with a repassivation of the material in the wear track. Furthermore, this behavior can be also related with the formation of a mixed oxide layer in the contact region as a result of corrosion and wear products released during mechanical interaction, creating a protective barrier between cp-Ti substrate and the corrosive medium $[2,15,77,78]$. A quick repassivation was observed when the mechanical sliding was ceased, as shown by the OCP values increase, however, to lower values than the ones existing prior to reciprocating sliding action. When the alumina ball was loaded on PEO_CE, 8,10 samples, the OCP remained constant as the reciprocating sliding took place (Fig. 3a). This indicates that the oxide film, during an ample time of sliding, was able to protect $\mathrm{cp}$-Ti substrate against corrosion. After a few min of sliding, the OCP gradually decreased a few millivolts, eventually due to wear of the topmost film layers. After sliding, the OCP gradually increased till it achieves a steady state value similar to the level before mechanical action. This complete recovery can be related with a re-growth of the passive film in the wear track presenting similar electrochemical characteristics as before mechanical action [2]. The improved tribocorrosion behavior of PEO_CE, 8,10 samples can be related with the significantly thicker oxide film grown during a longer processing time, exhibiting improved protective features when compared to the thinner film grown on PEO_CE,8,5.

For PEO_C $\beta, 8,5$ and PEO_C $\beta, 25,10$ samples, a dissimilar behavior was detected. Once the mechanical action was started, there was no drop in OCP values, and these were remained unchanged during the whole duration of sliding (Fig. 3a). The corrosion and tribocorrosion behaviors of the 
anodic films synthesized in the $\mathrm{C} \beta$ electrolyte were undoubtedly better than for cp-Ti_Reference and PEOtreated samples in $\mathrm{CE}$ electrolyte. The same trend was observed by Oliveira et al. [63] after tribocorrosion studies carried out in PEO-treated samples. They observed that the electrochemical behavior of all PEO-treated samples was improved as compared to cp-Ti group, from the point of view of both corrosion and tribocorrosion.

The COF evolution during sliding action for cpTi_Reference and PEO-treated samples is depicted in Fig. 3b. Furthermore, in Table 3 are shown the mean COF values measured during rubbing, after the run-in period. The run-in-period is correspondent to approximately the first $150 \mathrm{~s}$ of sliding and is induced by wear of the surface asperities and consequent particle introduction into the contact region [77]. In the case of cp-Ti_Reference samples, the COF was oscillating around a mean value of 0.59 during the total duration of the tribological contact. The COF measurements for PEO-treated samples were significantly higher than the ones recorded for cp-Ti_Reference specimens except for PEO_C $\beta, 25,10$ samples, as shown in Fig. $3 \mathrm{~b}$ and Table 3. The mean $\mathrm{COF}$ registered for PEO_C $\beta, 25,10$ samples was around 0.61 . The differences found between the different groups of samples for COF evolutions during sliding action, may be attributed to the dissimilar surface characteristics of the anodic films, namely, morphology/topography, chemical composition, and crystalline structure.

During PEO process, high temperatures can be reached (as high as $2400{ }^{\circ} \mathrm{C}$ [72] ) at Ti material surfaces, associated with plasma discharges. This effect can result in the conversion of the growing film into crystalline phases, namely, anatase (A) and rutile (R), which can confer higher hardness to the anodic films [79] and enhanced biological performance than the presence of an amorphous oxide film $[68,80,81]$.

In the present study, after tribocorrosion experiments, it was concluded that PEO_CE, 8,10 samples showed the best tribocorrosion performance, from the electrochemical point of view, among those samples anodized in the CE electrolyte. Furthermore, among the groups of samples

Table 3 COF mean values recorded during reciprocating sliding tests for $\mathrm{cp}-\mathrm{Ti}$ _Reference and PEO-treated samples

\begin{tabular}{ll}
\hline Group of samples & COF $( \pm$ SD $)$ \\
\hline cp-Ti_Reference & 0.59 \\
PEO_CE, 8,5 & $0.68 \pm 0.04^{*}$ \\
PEO_CE, 8,10 & $0.66^{*}$ \\
PEO_C $\beta, 8,5$ & $0.83 \pm 0.04^{*}$ \\
PEO_C $\beta, 25,10$ & 0.61 \\
\hline
\end{tabular}

* Significantly different from cp-Ti_Reference and PEO_C $\beta, 25,10$ samples; $p<0.05$ anodized in the C $\beta$ electrolyte, PEO_C $\beta, 25,10$ specimens were the ones that displayed enhanced wear/corrosion behavior. XRD spectra of PEO_CE,8,10 and PEO_C $\beta, 25,10$ samples are shown in Fig. 4a, b. In both groups of samples, $\mathrm{R}$ and $\mathrm{A} \mathrm{TiO}_{2}$ phases were identified, as already registered in others similar studies $[16,61,73]$. After the analyzes of the X-ray diffractograms, a different relative proportion of the polymorphs of $\mathrm{TiO}_{2}$ between PEO_CE, 8,10 and PEO_C $\beta, 25,10$ samples was found. The R/A ratio for PEO_C $\beta, 25,10$ specimens was higher (R/A ratio $=1.4)$ than in the case of PEO_CE, 8,10 samples (R/A ratio $=0.7$ ). This could be a reason of the better tribocorrosion performance exhibited by PEO_C $\beta, 25,10$ samples, as discussed in the following section.

\subsubsection{Wear Track Analysis}

The representative wear tracks of cp-Ti_Reference and PEO-treated samples after reciprocating sliding tests are shown in Fig. 5. The maximum depths of the wear tracks were calculated from the wear track profiles and are shown in Table 4.

The wear scar of cp-Ti_Reference (Fig. 5a) is characterized by sliding wear marks aligned in the pin movement direction indicating the occurrence of abrasion during rubbing. During sliding action, the release of wear particles from the contact surfaces may occur becoming introduced and entrapped in the contact region and lead to wear by abrasion of the surface $[15,77,78]$. Furthermore, it can be observed that plastic deformation of the cp-Ti surface occurred along the wear track as an effect of the interaction of cp-Ti with a harder ceramic counterbody (alumina). The maximum wear track depth for cp-Ti_Reference samples was $16 \pm 5.66 \mu \mathrm{m}$ (Table 4).

Sliding wear grooves were also present in the wear track of PEO_CE,8,5 samples showing the occurrence of abrasive wear of the anodic film (Fig. 5b). Furthermore, it is noticed that the oxide film detachment in the outermost parts of the scar, indicating a high brittleness of the film. In the central part of this wear track, there is a darkest zone which can be associated to wear debris and corrosion products released during the tribocorrosion action, which have became entrapped into the contact region and formed a mixed oxide layer, as discussed previously. The presence of anodic film elements in this area was confirmed by EDS (results not shown). This is an indicator that the anodic film on PEO_CE,8,5 samples was not fully removed from the contact area during reciprocating sliding as also suggested by the relation between the thickness of this film (film thickness $\approx 11.34 \pm 0.56 \mu \mathrm{m}$, Table 2 ) and the maximum depth of this wear scar (maximum depth $\approx 10.00 \mu \mathrm{m}$, Table 4). The wear track of PEO_CE, 8,10 samples (Fig. 5c) is also characterized by the anodic film 

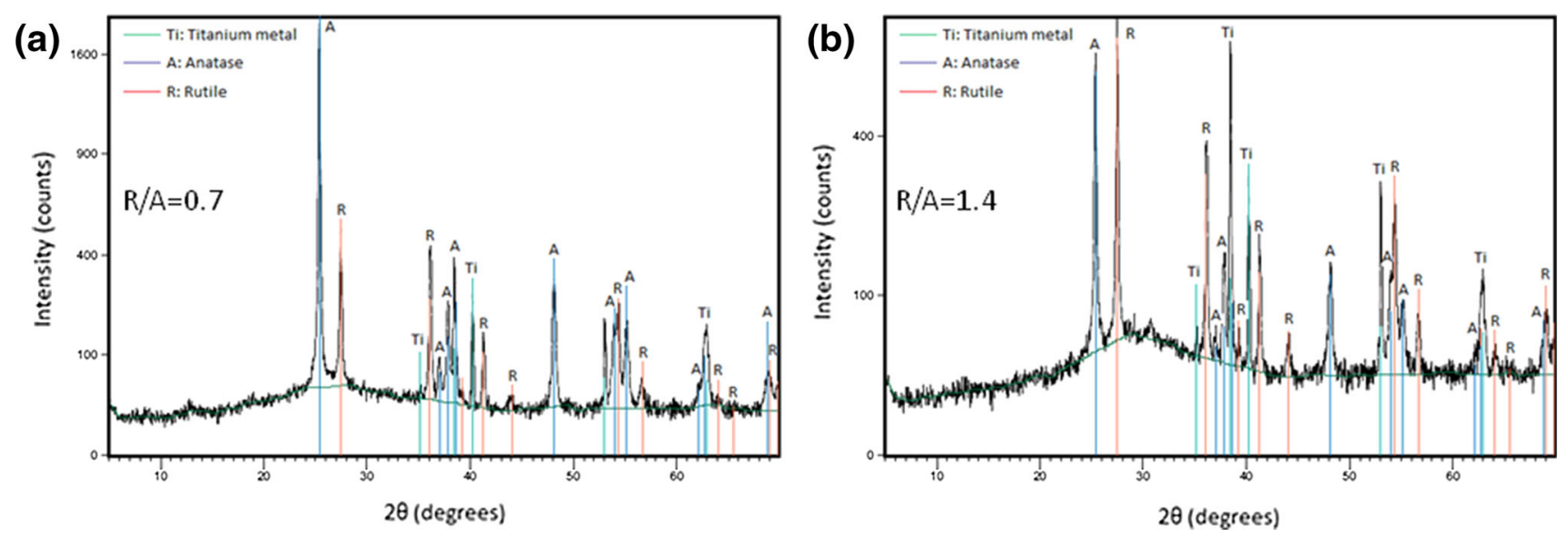

Fig. 4 XRD spectra of a PEO_CE,8,10 and b PEO_C $\beta, 25,10$ samples. The R and A ratio (R/A) present on each different sample is depicted in the correspondent spectrum

detachment in the outermost parts. In this case, it is not noticed the presence of abrasion wear marks. The maximum depth reached in this wear scar was of approximately $13.5 \pm 2.12 \mu \mathrm{m}$ (Table 4), and the thickness of the anodic film was around $15.74 \pm 0.26 \mu \mathrm{m}$ (Table 2), which indicates that cp-Ti substrate surface probably was protected by the anodic film during the sliding action, as previously deducted from the small OCP variation registered for these films during sliding action (Fig. 3a).

The FESEM micrograph of the wear track of PEO_C $\beta, 8,5$ samples shows that, as a consequence of sliding, the surface of the samples was polished. Although, in this scar, there some cracks are visible indicating the possibility of film detachment (Fig. 5d). Analyzing the wear track profile, it was detected a negligible depth which suggests that the anodic oxide film has not been removed from the worn region. In the case of PEO_C $\beta, 8,5$ samples (Fig. 5d), the wear track is almost imperceptible when compared with the one obtained for the PEO_CE,8,5 samples (Fig. 5b). Finally, the wear track for the PEO_C $\beta, 25,10$ samples (Fig. 5e) is characterized by smooth parts (polishing effect) what can be attributed to the removal of surface asperities as a consequence of the reciprocating sliding. No plowing lines or severe deformation in the wear track was detected in this case. Analyzing the correspondent wear track profile, it was also not detected a significant depression what confirms the presence of the anodic film in the frictional area.

From the results described above, it seems that the electrolyte composition plays a huge influence on the mechanical wear resistance of anodized samples by decreasing the mechanical damage of the materials surface. However, there is an important concern on the morphological aspect of PEO-treated samples after tribocorrosion action: the typical porous morphology of the anodic films is not observed in the wear track area as shown in Fig. 5. This might indicate that during implantation, the wear induced on implant surface will change its surface features in a way that the morphology of the porous structure will not be the same as found before implantation. Recently, Mints et al. [82] studied whether the integrity of common implant surface modifications was retained after insertion. In this study, anodized experimental implants were inserted into polyurethane foam blocks at maximum torque of $37 \mathrm{~N} \mathrm{~cm}$. The authors found out that in some areas of the implant the anodized layer had been completely removed and in other cases it remained intact and rough. By other hand, the study performed by Patel et al. [83] revealed that titania nanotubes grown on Ti6Al4 $\mathrm{V}$ rods remained stable and maintained their structural integrity during insertion and pullout test into a simulant bone. The authors concluded that the high stress during insertion of anodized rods may play a beneficial role in preventing micromotion between the bone and implant. Nevertheless, The migration of osteoblasts as well as the osseointegration process might be influenced by the absence of a porous structure. Therefore, this is an issue of upmost importance and further studies must be conducted aiming to investigate the impact of the implant surface damage during insertion on bone-implant integration. For that purpose, it would be interesting the assessment of osteoblasts adhesion and proliferation on the wear tracks of PEO-treated samples resulting from tribocorrosion action. Furthermore, the influence of tribocorrosion action on osteoblastic cells would be also of valuable interest. Recently, Runa et al. [84] studied the impact of an osteoblastic cell layer on bio-tribocorrosion performance of Ti6Al4 V. The results showed that the presence of an osteoblastic cell layer on the implant surface significantly influences the tribocorrosion behavior of Ti6Al4V alloy. A similar approach could be used to study 


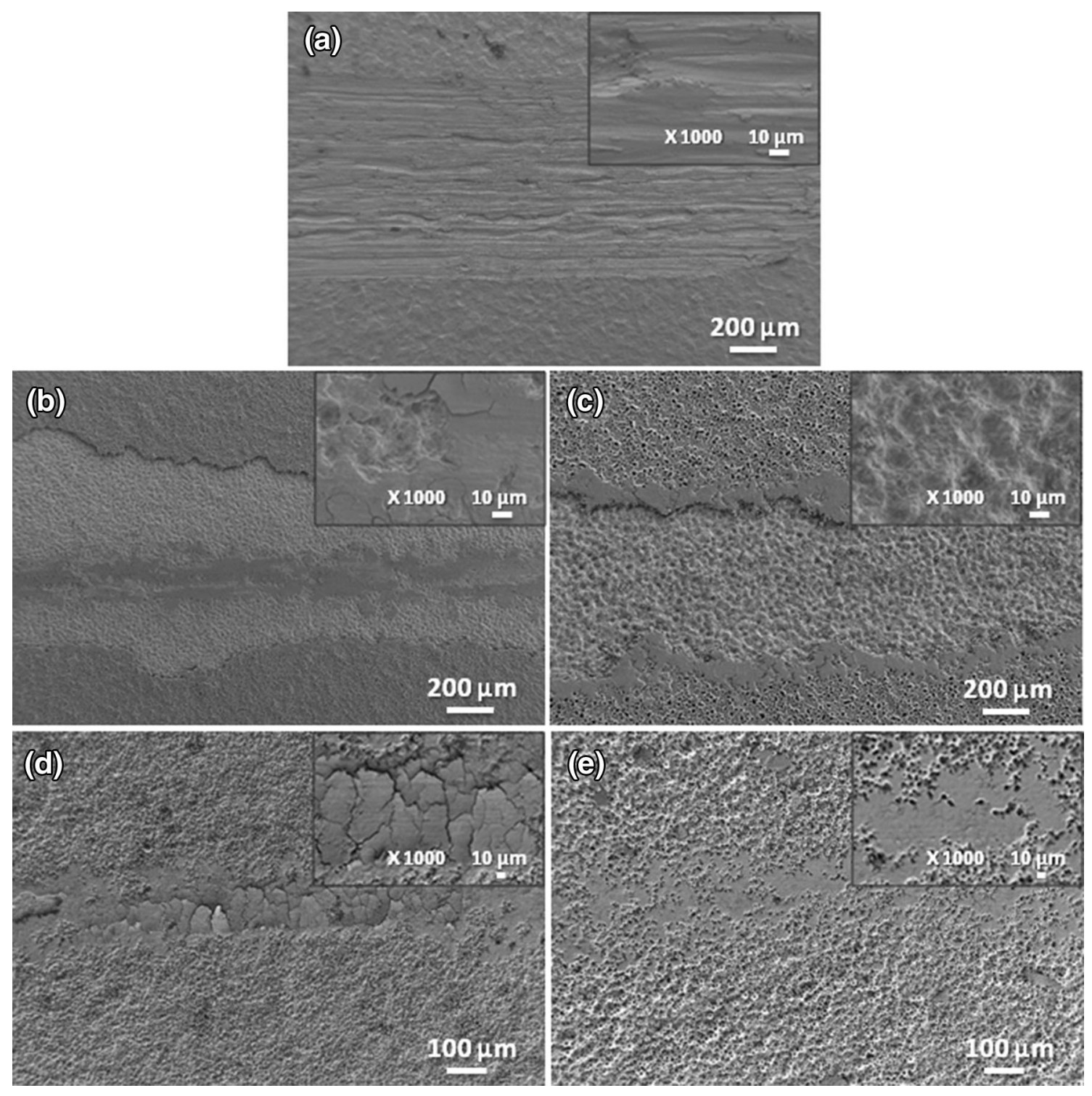

Fig. 5 FESEM micrographs of the wear tracks for the a cpTi_Reference, b PEO_CE,8,5, c PEO_CE,8,10, d PEO_C $\beta, 8,5$, and e PEO_C $\beta, 25,10$ samples, after reciprocating sliding tests (test

Table 4 Maximum depth mean values measured in the wear tracks for the cp-Ti_Reference and PEO-treated samples after reciprocating sliding tests

\begin{tabular}{ll}
\hline Group of samples & Maximum depth in the wear track $(\mu \mathrm{m} \pm \mathrm{SD})$ \\
\hline cp-Ti_Reference & $16.00 \pm 5.66$ \\
PEO_CE, 8,5 & 10.00 \\
PEO_CE, 8,10 & $13.5 \pm 2.12$ \\
PEO_C $\beta, 8,5$ & n.s. \\
PEO_C $\beta, 25,10$ & n.s. \\
\hline
\end{tabular}

n.s. means that measurements were not significant conditions: $2 \mathrm{~N}, 3 \mathrm{~mm}, 2 \mathrm{~Hz}, 720 \mathrm{~s}$ ). All the SEM pictures are shown at lower and higher magnification (right upper corner)

the effect of PEO-treated samples degraded by tribocorrosion on osteoblastic cell functions. To address this issue, the investigation of the influence of wear particles/corrosion products, resulting from tribocorrosion of PEO-treated samples, on osteoblastic cell functions, would be also an interesting approach.

Both the tendency for corrosion and mechanical wear resistance were improved on cp-Ti samples anodized in $C \beta$ electrolyte when compared with the samples anodized in CE electrolyte. These differences can be associated with the crystalline structure of the anodic films. Alves et al. 
[61] studied the tribocorrosion behavior of anodic films produced in an electrolyte containing $\beta$-glycerophosphate and different concentrations of calcium acetate. The authors hypothesized that the reason for the much better tribocorrosion behavior of samples anodized in the higher calcium acetate concentration electrolyte, was the crystalline structure (presence of anatase/rutile) and calcium content on those samples. More recently, Oliveira et al. [58] produced and investigated the tribocorrosion behavior of porous $\mathrm{TiO}_{2}$ anodic films containing calcium, phosphorous, and magnesium. They concluded that micro-arc oxidation treatments induced the formation of a nanocomposite gradient crystalline structure and that the addition of magnesium to the anodizing electrolyte increased the percentage of crystalline rutile, which are thought to be determining factors for achieving an improved tribocorrosion behavior of the surfaces. In the present study, cp-Ti samples anodized in the CE electrolyte are characterized by a higher proportion of anatase while PEO_C $\beta, 25,10$ samples display a higher proportion of rutile (Fig. 4a, b), which is harder and more wear resistance than anatase. Previous results obtained by reactive pulse magnetron sputtering have shown that anatase phase has a hardness between 6 and $8 \mathrm{GPa}$, while rutile phase is linked with a drastic increase of hardness values up to $17 \mathrm{GPa}$ [85, 86]. For rutile layers deposited by Spotless arc Activated Deposition, hardness values up to $12 \mathrm{GPa}$ could be determined by Modes et al. [86]. In agreement, Kaczmarek et al. [87] reported that the nanocrystalline $\mathrm{TiO}_{2}$-rutile thin film as-deposited using high-energy reactive magnetron sputtering, had high hardness $(14.3 \mathrm{GPa})$, while the $\mathrm{TiO}_{2^{-}}$ anatase films as-deposited by low pressure hot target reactive sputtering were four times lower $(3.5 \mathrm{GPa})$. These values are significantly lower to the ones found in literature for human femoral bone, which ranged from 0.234 and $0.760 \mathrm{GPa}[88,89]$. This discrepancy on the hardness values between $\mathrm{TiO}_{2}$ crystalline and human cortical bone might indicate that during implant insertion bone particles will remain in peri-implant areas. Such observation was recently reported in the experiment performed by Patel et al. [83] where they concluded that after insertion of anodized Ti6Al4V rods into simulant bone, loose debris or particulates of simulant bone were accumulated on the surface.

Rutile is characterized by improved corrosion resistance as compared to anatase phase $[52,90]$. Furthermore, it is also reported in literature the formation of well-adherent rutile $\mathrm{TiO}_{2}$ phase on cp-Ti with improved wear resistance and reduced friction coefficient [3]. In this work, lower values of $\mathrm{COF}$ were registered during the almost time of the sliding action for PEO_C $\beta, 25,10$, when compared to PEO_CE, 8,10 samples (Fig. 3b). These differences can be related with the ability of rutile to behave as a solid

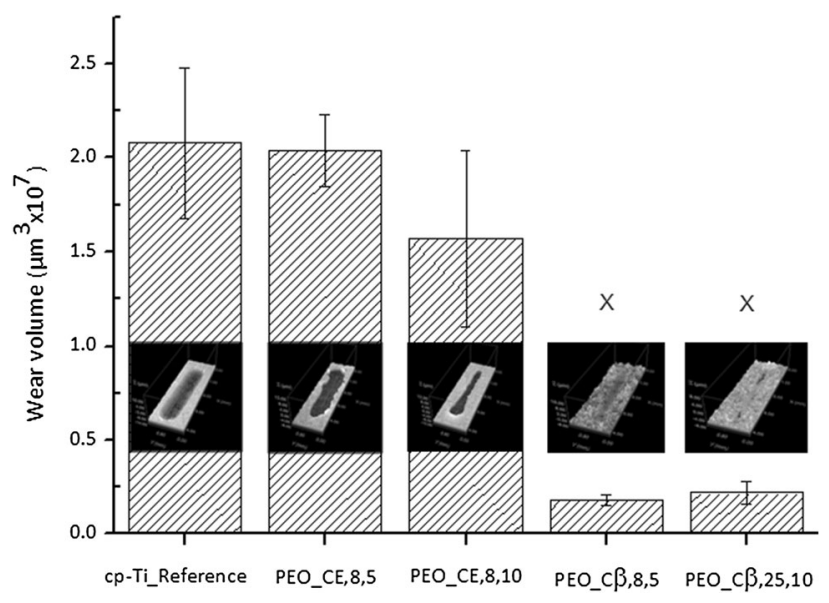

Fig. 6 Wear volume measurements of the wear tracks for the cpTi_Reference and PEO-treated samples after reciprocating sliding tests (test conditions: $2 \mathrm{~N}, 3 \mathrm{~mm}, 2 \mathrm{~Hz}$ and $720 \mathrm{~s}$ ). For each group of samples, the correspondent confocal image of the wear tracks is shown. The different groups of samples are identified in the figure. (times symbol), significantly different from cp-Ti_Reference, PEO_CE,8,5, and PEO_CE,8,10 samples; $p<0.05$

lubricant [3], leading consequently to an enhanced wear resistance of the anodic films produced on PEO_C $\beta, 25,10$ samples.

Wear volume measurements were carried out from the wear track profiles of cp-Ti_Reference and PEO-treated samples and the results are depicted in Fig. 6. In this figure, for each different group of samples, was also included the confocal image of the correspondent wear track. The wear volumes measured for cp-Ti_Reference, PEO_CE,8,5, and PEO_CE, 8,10 samples were significantly higher than the ones calculated for samples anodized in the $C \beta$ electrolyte (PEO_C $\beta, 8,5$ and PEO_C $\beta, 25,10$ ), as shown in Fig. 6. These results are in accordance with the differences observed between the morphologies of the wear tracks previously analyzed and discussed (Fig. 5). From the electrochemical point of view, the anodized samples in the CE presented an improved behavior during sliding when compared to cp-Ti_Reference specimens. However, after wear volume measurements, it seems that the mechanical action strongly contributed for the detachment of the anodic film, and thus for material degradation (Fig. 6).

\subsection{Osteoblastic Cell Response}

\subsubsection{SEM and CLSM Analysis}

In this study, anodic oxide films reveal different morphology, topography, chemical composition, and crystalline structure, which are key factors for cell adhesion, proliferation, and differentiation [16, 36, 41]. Cell adhesion is one of the initial critical stages to subsequent 
proliferation and differentiation [36, 91, 92] and in the present study it was addressed by SEM and CLSM imaging.

MG63 cells were cultured on standard polystyrene culture wells (control), cp-Ti_Reference, PEO_CE,8,10, and PEO_C $\beta, 25,10$ samples. The PEO-treated samples were selected in accordance with the best tribocorrosion results obtained for each electrolyte, as revealed and discussed previously. The representative SEM micrographs (available at lower and higher magnifications) of the cell morphology and distribution on the different groups of samples for 1, 3, and 7 days of culture time are shown in Fig. 7.

At day 1, MG63 cells were well adhered and spread on the materials surfaces and presented an elongated morphology, similar to the one of the cells attached on control wells. Cells were isolated and with a relatively homogeneous distribution along the materials surfaces (Fig. 7). After 3 days of culture, the cells were already organized into interconnected groups, both in control and on the anodized samples; however, this cellular organization was poor defined in the case of PEO_CE, 8,10 when compared with PEO_C $\beta, 25,10$ samples (see higher magnification SEM pictures). SEM images at days 3 and 7 illustrate that the number of adhered cells increased during the culture time on all the surfaces. Nevertheless, both at days 1 and 3, it seems that the number of adhered cells was higher on PEO_C $\beta, 25,10$ surfaces than on cp-Ti_Reference. Finally, at day 7, the control wells and the surface of cp-Ti_Reference and anodized samples were completely covered by an abundant cell layer. It seems that cells adapted successfully to the materials surfaces both at day 1 , as isolated and distributed cells, and also at later culture times, as a continuous cell layer.

CLSM images (Fig. 8) show that MG63 cells cultured on cp-Ti_Reference and PEO-treated samples have an elongated morphology, cell-to-cell contact, and a well-organized F-actin cytoskeleton that stains intensively at the cell limits. This is a relevant information regarding cell behavior, as F-actin is highly concentrated just beneath the plasma membrane and controls the shape and cell motility, modulating cellular mechanics subjacent to proliferation and differentiation events [93, 94]. In addition, it provides the molecular basis for many of the mechanical properties of the cytoplasm [95]. Figure 8 shows representative images of 3-day cultures. In agreement with that observed in SEM, PEO_C $\beta, 25,10$ samples presented a high number of cells compared to PEO_CE, 8,10 specimens.

The results mentioned above show that osteoblasts were able to adhere, spread, and proliferate during the culture time, on all the samples. However, some important differences were noticed. After 1 and 3 days of culture, a higher number of adhered cells is present on PEO_C $\beta, 25,10$ surfaces when compared both with cp-Ti_Reference and PEO_CE, 8,10 surfaces. These results show that cell adhesion and growth were improved on PEO_C $\beta, 25,10$ surfaces, suggesting a more favorable cell response.

\subsubsection{MTT Assay}

The viability of MG63 cells seeded on standard polystyrene culture wells (control), cp-Ti_Reference, PEO_CE, 8,10 , and PEO_C $\beta, 25,10$ samples was evaluated by of the MTT reduction assay, after 1, 3, and 7 days of incubation, as shown in Fig. 9. The MTT reduction is attributed to mitochondrial succinate dehydrogenase redox activity. Thus, the results presented in Fig. 9 are proportional to cell metabolism, and therefore, to cell viability. Furthermore, an increase in the cell viability is an indicator of cell proliferation $[36,96]$. In the first days of culture (days 1 and 3), the cell growth was not too much noticeable what can be associated to the adhesion process and the adaptation of the cells to the culture environment, i.e., the culture conditions and the culture materials, however, a significant increase was observed from day 3 to day 7 for all the samples. This increase might be related with the continuous surface conditioning due to the deposition of molecules present in the culture medium and, in the case of PEO-treated samples, also due to the simultaneous exchange reactions between the materials surfaces and the medium (i.e., as dissolution/deposition processes). These events lead to progressively improved surfaces for cell growth. It is worth to note that the initial lag phase is more notorious on PEO_CE, 8,10 samples, for which similar absorbance values were observed at days 1 and 3. This suggests the need of a longer time period for the beginning of the exponential cell growth, as compared to the other surfaces. These results, together with SEM observations previously discussed, suggest that all the samples are cytocompatible. This is in agreement with studies indicating that $\mathrm{Ti}$ is a biocompatible substrate for cell culturing [1, 36, 46]. The viability/proliferation of MG63 cells cultured on PEO_CE, 8,10 samples was similar to the one of cells cultured on cp-Ti_Reference samples during the whole culture time. Nevertheless, in accordance with the SEM results previously discussed, the cells cultured on PEO_C $\beta, 25,10$ samples exhibited significantly higher values of metabolic activity at days 1 and 3 and similar at day 7, compared to cp-Ti_Reference specimens. These results suggest that PEO_C $\beta, 25,10$ samples allowed an improved cell response in the first days of culture than on etched cpTi surfaces.

As above shown and discussed, PEO_CE, 8,10 and PEO_C $\beta, 25,10$ samples display a porous and rougher morphology/topography when compared to cp-Ti-etched samples. Pore sizes up to $12 \mu \mathrm{m}$ were found on 

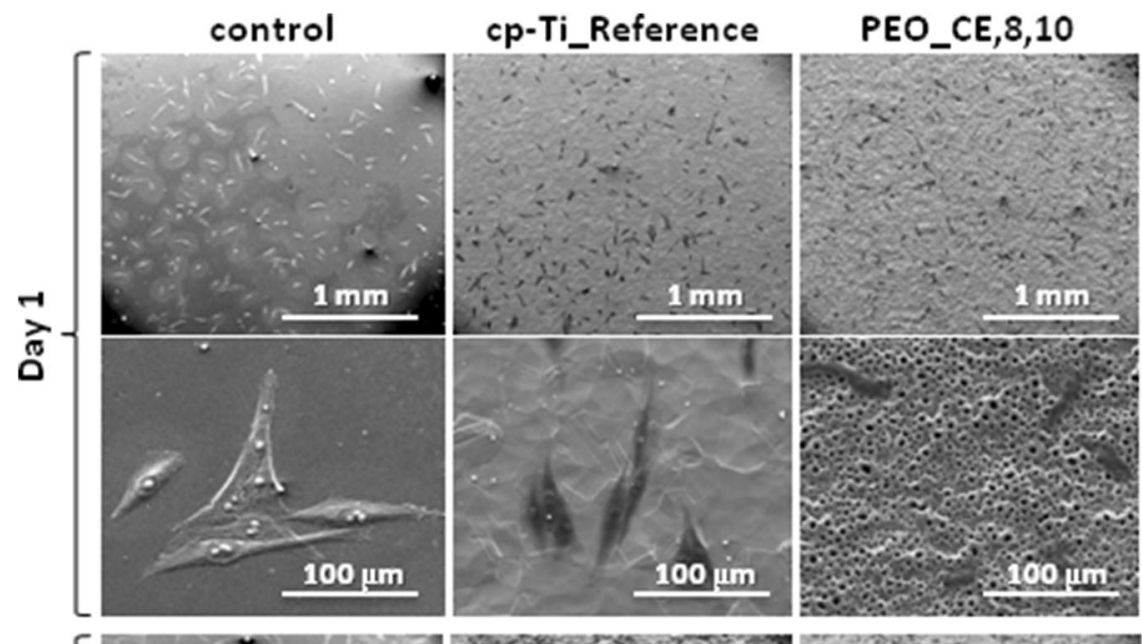

\section{PEO_C $\beta, 25,10$}
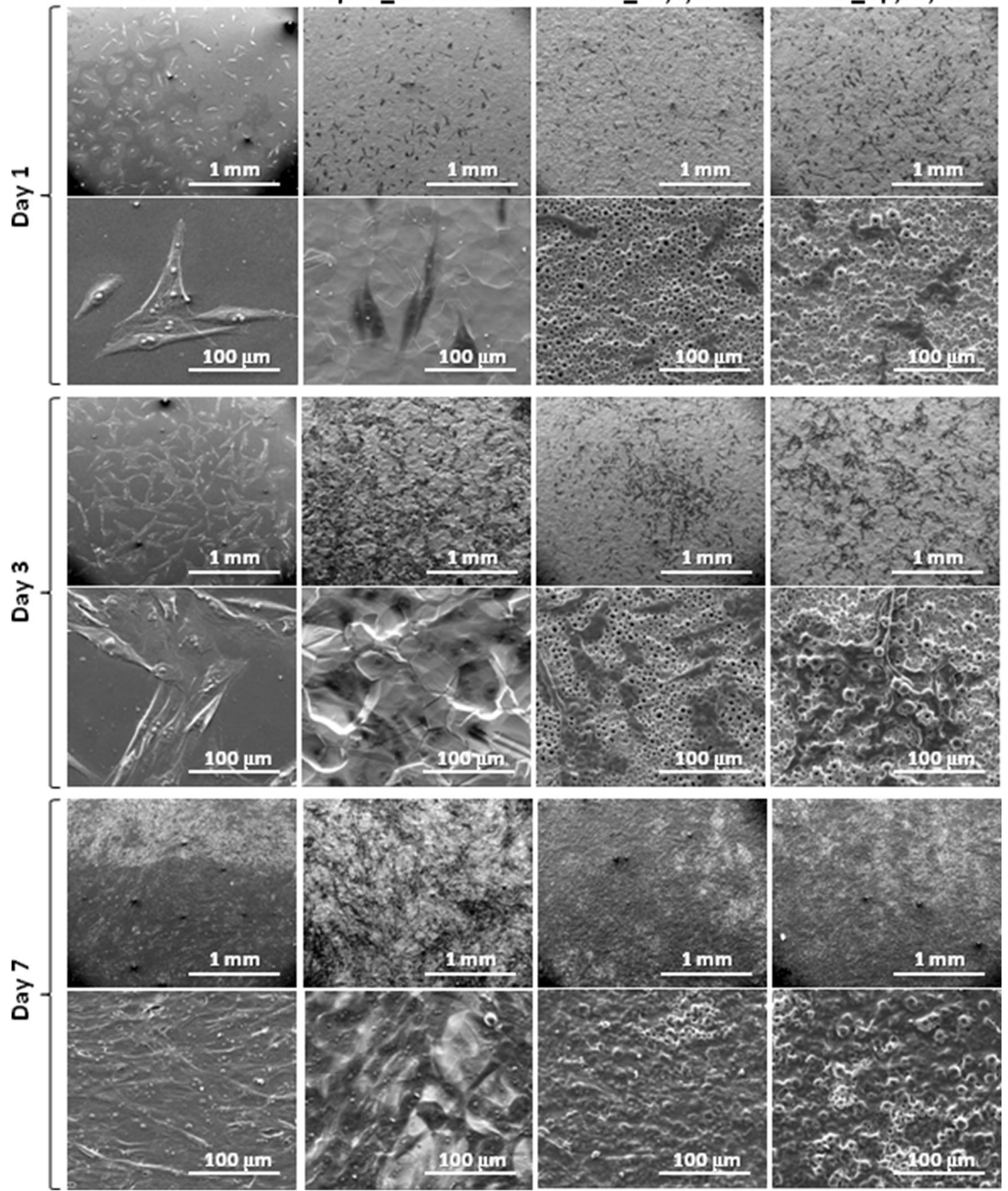

Fig. 7 Lower and higher magnification SEM micrographs of MG63 cells cultured on standard culture materials (control), cp-Ti_Reference, PEO_CE,8,10, and PEO_C $\beta, 25,10$ samples, after 1, 3, and

PEO_CE, 8,10 samples, while PEO_C $\beta, 25,10$ displayed pores up to $6 \mu \mathrm{m}$ diameter. It is well known that after cell attachment, cell spreading is the following event for cellsubstrate interaction. The topographical features of the substrate modulate fibronectin and vitronectin integrin receptors therefore determining variations in shape and
7 days of incubation. The different groups of samples are properly identified in the figure

spreading of cells and ultimately, dictating cell adhesion and growth [41]. As found from the study performed by Das et al. [35], the high surface roughness of anodized Ti samples is a crucial factor for improved cell attachment and proliferation. Furthermore, as Korkusuz et al. [97] reported, the cell adhesion and detachment strength 

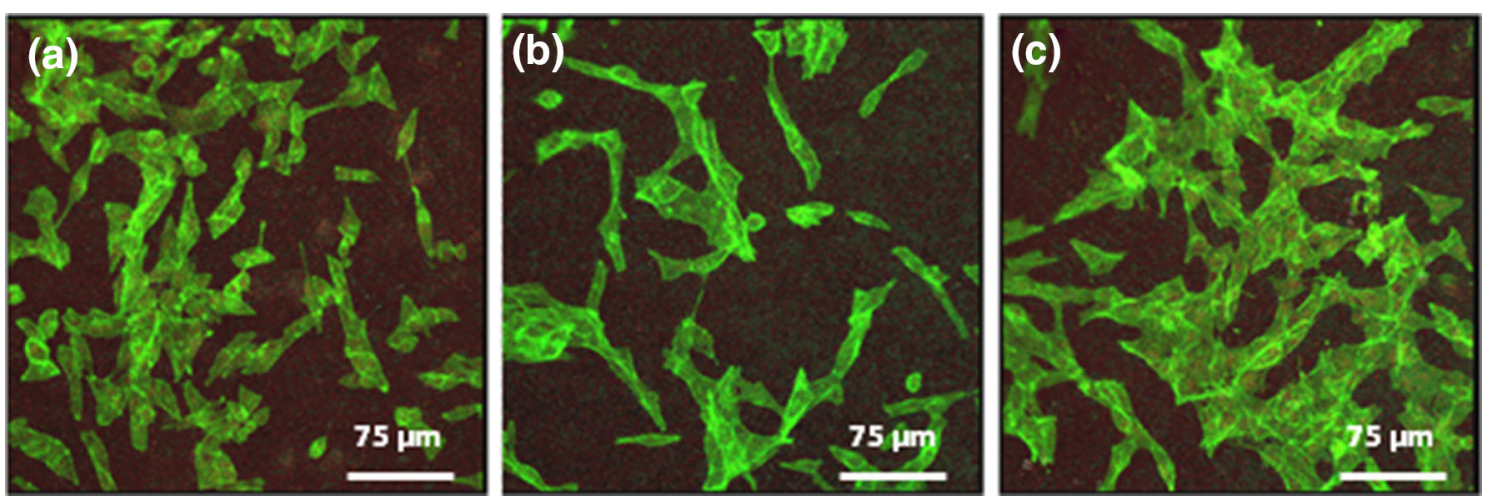

Fig. 8 CLSM micrographs of MG63 cells cultured on a cp-Ti_Reference, b PEO_CE,8,10, and c PEO_C $\beta, 25,10$ samples, after 3 days of incubation

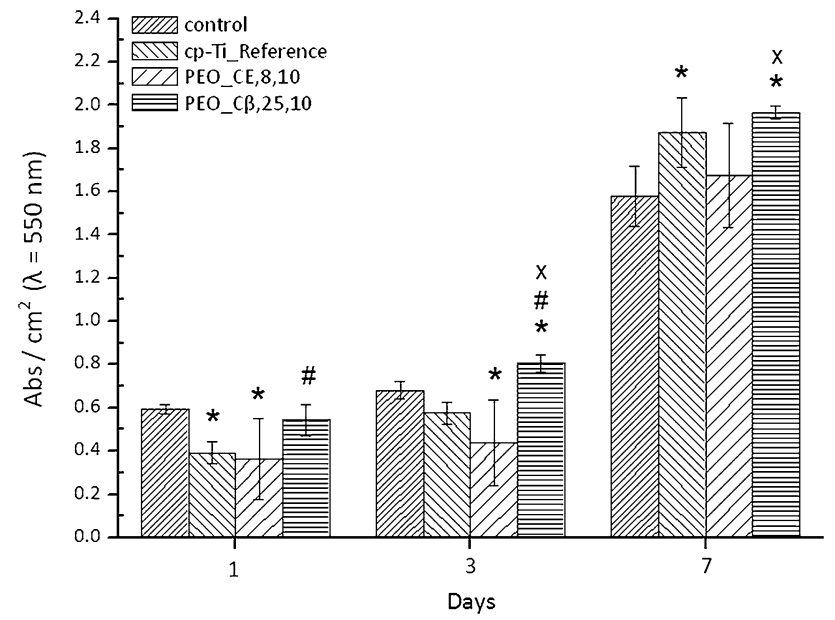

Fig. 9 Viability of MG63 cells cultured on standard culture materials (control), cp-Ti_Reference, PEO_CE,8,10, and PEO_C $\beta, 25,10$ samples, after 1, 3, and 7 days of incubation. For each culture time: (asterisk), significantly different from control samples; (hash symbol), significantly different from cp-Ti_Reference; (times symbol), significantly different from PEO_CE, 8,10 samples; $p<0.05$

increases as surface roughness raises. Nevertheless, cell functions are not only affected by roughness but also by surface micro-structure and composition [41]. Microporous structures of anodic oxides produced by PEO have been also found to influence biological responses. Concerning pore size, the results in literature are still controversial. It is reported that anodic films with pore sizes up to $2 \mu \mathrm{m}$ induced a high level of cell attachment [16, 41]. Furthermore, it was also found that PEO films with average pore size of $2-10 \mu \mathrm{m}$ promoted attachment and spreading of osteoblastic cells [98]. In addition, pore sizes ranging from 100 to $400 \mu \mathrm{m}$ were also reported to enhance bone ingrowth [97]. In the present study, the cell attachment and viability/proliferation were enhanced by the roughened PEO_C $\beta, 25,10$ surfaces with pore size comparable to the ones already found in literature as promoters of osteoblastic cell functions, and therefore they seem to be potential candidates to enhance the osseointegration process.

The chemical composition of the anodic films is also a relevant parameter which might contribute for an improved cell behavior. The beneficial effect of the anodic treatments in Ca-P solutions on the surface biocompatibility of Ti has been suggested by previous studies [41, 46, 98]. Anodizing processes involving $\mathrm{Ca}$ - and $\mathrm{P}$-based electrolytes result in the development of an oxide film containing bioactive compounds incorporated into its structure. The amount of these elements incorporated into the films plays a crucial role on its biological performance. It is believed that increasing the mineral content at the bone-implant interface results in a microenvironment that promotes a faster bone formation and bone ingrowth [76]. This factor can be associated with the improved biological performance that PEO_C $\beta, 25,10$ surfaces displayed when compared with cp-Ti_Reference samples. Once in the culture medium, $\mathrm{Ca}$ and $\mathrm{P}$ ions present in the anodic film of the PEO_C $\beta, 25,10$ samples, can be released from the surface for the extracellular medium and penetrate the cell membrane or activate membrane-bound receptors [41]. Zhu et al. [41] have reported that $\mathrm{Ti}$ implants with anodic oxide films containing either $\mathrm{P}$ or $\mathrm{Ca}$ and $\mathrm{P}$, showed improved cell attachment and proliferation, and in vivo studies revealed a significant higher percentage of bone contact. This can be explained by the formation of biochemical bonding in the interface between bone and anodized surfaces, which have bioactive elements incorporated [41]. Li et al. [46] also concluded that the presence of $\mathrm{Ca}$ and $\mathrm{P}$ in the oxide films enhanced the bonding strength between PEO-treated $\mathrm{Ti}$ implants and bone. It has been demonstrated that anodic films produced by PEO treatments and doped with $\mathrm{Si}, \mathrm{Ca}$, and $\mathrm{Na}$ possess a good ability to form a biomimetic apatite layer onto their surfaces once in contact with simulated body fluid solutions [51, 56, 67].

As aforementioned, besides the important role of the amount of $\mathrm{Ca}$ and $\mathrm{P}$ that is incorporated into the anodic 
oxide film, its crystalline structure is also of fundamental importance in determining the cell response [68]. The natural oxide film which is spontaneously formed on $\mathrm{Ti}$ surfaces when exposed to aerated environments is generally amorphous [69]. In this study, the anodic films presented a crystalline structure where both rutile and anatase $\mathrm{TiO}_{2}$ phases were identified. It is known that anatase plays an important role in proliferation and cell morphology [99]. Furthermore, it is also reported that rutile phase improves osteoblast adhesion in vitro and enhance the percentage of bone-to-implant in vivo [81]. The results showed that cells cultured on PEO_C $\beta, 25,10$ samples presented an improvement in the cell viability/proliferation compared to the cp-Ti_Reference specimens. The crystalline structure of the anodic films present on these samples can be another factor exerting a beneficial effect in the biological behavior.

The surface wettability is known to play a crucial role in the cell attachment, since the adhesion phase involves physicochemical linkages between cells and surfaces [35, 41]. Changes on surface wettability can lead to alterations in the adsorption of conditioning molecules influencing the cell attachment [41]. Hence, in this work, the surface wettability of cp-Ti_Reference, PEO_CE, 8,10, and PEO_C $\beta, 25,10$ was investigated by WCA measurements and the results are depicted in Fig. 10. Significantly higher and lower WCA values were registered for PEO_C $\beta, 25,10$ and PEO_CE, 8,10 samples, when compared to cpTi_Reference. Moreover, PEO_C $\beta, 25,10$ samples displayed significantly higher WCA than PEO_CE, 8,10 samples. Several studies have been already published showing that cells attach more efficiently to hydrophilic (WCA $<90^{\circ}$ ) when compared to hydrophobic surfaces $\left(\right.$ WCA $\left.>90^{\circ}\right)[35,41,68,100]$. However, in this work, a higher metabolic activity was observed for cells cultured on PEO_C $\beta, 25,10$ samples which are less hydrophilic than cp-Ti_Reference samples (Fig. 10). This observation can be related with the fact that cell responses (e.g., adhesion and proliferation), beyond wettability, are influenced by a set of factors, namely, surface morphology/topography, chemistry, and crystalline structure, acting all simultaneously. Synergistic and/or antagonistic effects involving the different surface parameters may happen and influence osteoblastic cell responses.

\section{Conclusions}

The influence of the anodization parameters, namely, process duration and electrolyte composition, on the surface features of the anodic films was investigated. Furthermore, the tribocorrosion behavior of titanium oxide films and their osteoblastic cell response were studied.

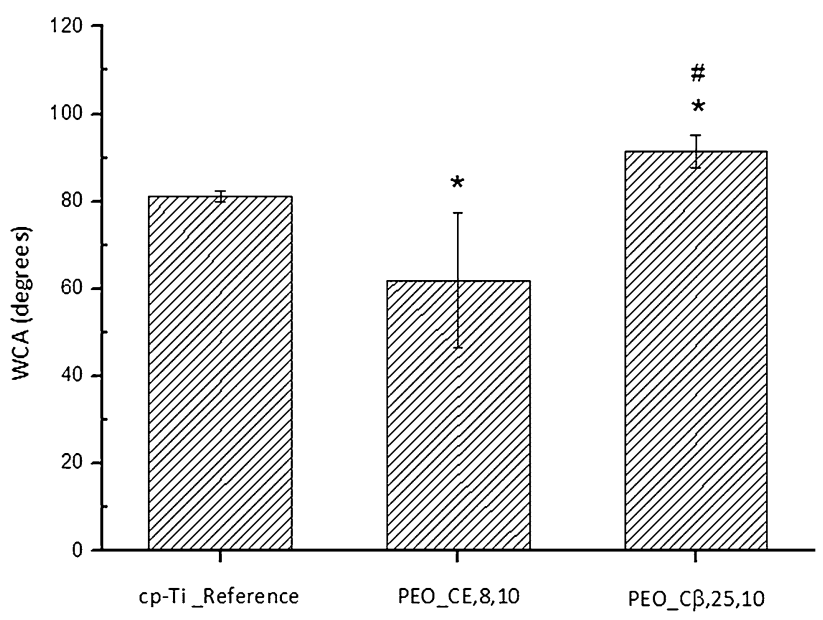

Fig. 10 WCA measurements on cp-Ti_Reference, PEO_CE,8,10, and PEO_C $\beta, 25,10$ samples. Different groups of samples are properly identified in the figure. (asterisk), significantly different from cpTi_Reference samples; (hash symbol), significantly different from PEO_CE, 8,10 samples; $p<0.05$

The main outcomes of this work are the following:

- Porous anodic oxide films were produced on cp-Tietched surfaces by PEO;

- By varying the PEO processing conditions, namely, the duration and electrolyte composition, anodic films with different features such as pore size, $R_{\mathrm{a}}$, thickness, chemical composition, and crystalline phase were synthesized;

- The electrolyte composition played a crucial role on the tribocorrosion performance of anodized samples. The specimens anodized in the $\mathrm{Ca}$ - and $\mathrm{P}$-based electrolyte at $25 \mathrm{~A} / \mathrm{dm}^{2}$ for $10 \mathrm{~min}$ (PEO_C $\beta, 25,10$ samples) revealed improved tribocorrosion behavior in AS, both in terms of tribological and electrochemical properties by decreasing the mechanical damage and tendency to corrosion. It is believed that the improved tribocorrosion behavior is related with the crystalline structure (mixture of anatase and rutile) of the anodic films, since PEO_C $\beta, 25,10$ samples exhibited a higher rutile/ anatase ratio, improving their mechanical and corrosion resistance.

- The MTT assay, in accordance with SEM observations, revealed that cell viability/proliferation was improved on PEO_C $\beta, 25,10$ samples.

- To overcome the limitations of the current study, the microbial behavior of PEO-treated samples should be further studied for assessment of interactions between microorganisms and the porous structures of the anodic films.

- Future studies should also investigate the relevance of implant surface damage during insertion on periimplant bone response. For that purpose, the following 
studies should be conducted: (i) study of the integrity of PEO-treated implant surfaces after insertion into simulant bone; (ii) assessment of osteoblast adhesion and proliferation on wear tracks of PEO-treated samples resulting from tribocorrosion action; (iii) influence of tribocorrosion action on osteoblastic cells cultured on PEO-treated samples and, last but not least, the (iv) investigation of the impact of wear particles/corrosion products resulting from tribocorrosion of PEO-treated samples on osteoblastic cell functions.

- Beyond the limitations already addressed, this study brings new insights on the surface features that may contribute for a better outcome of dental implants by improving their tribocorrosive and osteoblastic behavior after implantation.

Acknowledgments The authors would like to acknowledge the Erasmus Exchange programme of the EU for the partial funding of this project as well as the financial support from the project EMAITEK by the Basque Country Government. The authors also thank FMDUP for the financial support to conduct cell culture experiments.

Conflict of interest On behalf of all authors, the corresponding author states that there is no conflict of interest.

\section{References}

1. Song H-J, Kim M-K, Jung G-C, Vang M-S, Park Y-J (2007) The effects of spark anodizing treatment of pure titanium metals and titanium alloys on corrosion characteristics. Surf Coat Technol 201(21):8738-8745. doi:10.1016/j.surfcoat.2006.11.022

2. Vieira AC, Ribeiro AR, Rocha LA, Celis JP (2006) Influence of $\mathrm{pH}$ and corrosion inhibitors on the tribocorrosion of titanium in artificial saliva. Wear 261(9):994-1001. doi:10.1016/j.wear. 2006.03.031

3. Yetim AF (2010) Investigation of wear behavior of titanium oxide films, produced by anodic oxidation, on commercially pure titanium in vacuum conditions. Surf Coat Technol 205 (6): 1757-1763. doi:10.1016/j.surfcoat.2010.08.079

4. Yerokhin AL, Leyland A, Matthews A (2002) Kinetic aspects of aluminium titanate layer formation on titanium alloys by plasma electrolytic oxidation. Appl Surf Sci 200(1-4):172-184. doi:10. 1016/s0169-4332(02)00848-6

5. Chiang C-Y, Chiou S-H, Yang W-E, Hsu M-L, Yung M-C, Tsai M-L, Chen L-K, Huang H-H (2009) Formation of TiO2 nanonetwork on titanium surface increases the human cell growth. Dent Mater 25(8):1022-1029. doi:10.1016/j.dental.2009.03.001

6. Souza JC, Henriques M, Teughels W, Ponthiaux P, Celis J-P, Rocha LA (2015) Wear and corrosion interactions on titanium in oral environment: literature review. J Bio Tribo Corros 1(2):1-13

7. Oshida Y, Tuna EB, Aktoren O, Gencay K (2010) Dental implant systems. Int J Mol Sci 11(4):1580-1678. doi:10.3390/ ijms11041580

8. Kim H-K, Jang J-W (2004) Electrochemical corrosion behavior and MG-63 osteoblast-like cell response of surface-treated titanium. Met Mater Int 10(5):439-446. doi:10.1007/ bf03027346

9. Norowski PA, Bumgardner JD (2009) Biomaterial and antibiotic strategies for peri-implantitis. J Biomed Mater Res B 88B (2):530-543. doi:10.1002/Jbm.B.31152
10. Pye AD, Lockhart DEA, Dawson MP, Murray CA, Smith AJ (2009) A review of dental implants and infection. J Hosp Infect 72(2):104-110. doi:10.1016/j.jhin.2009.02.010

11. Taylor TD (1998) Prosthodontic problems and limitations associated with osseointegration. J Prosthet Dent 79(1):74-78. doi:10.1016/s0022-3913(98)70197-0

12. Mallia B, Dearnley PA (2007) The corrosion-wear response of Cr-Ti coatings. Wear 263(1):679-690

13. Cruz HV, Souza JCM, Henriques M, Rocha LA (2011) Tribocorrosion and bio-tribocorrosion in the oral environment: the case of dental implants. In: Davim JP (ed) Biomedical Tribology. Nova Science Pub Inc, Beijing, pp 1-33

14. Mathew MT, Abbey S, Hallab NJ, Hall DJ, Sukotjo C, Wimmer MA (2012) Influence of $\mathrm{pH}$ on the tribocorrosion behavior of $\mathrm{CpTi}$ in the oral environment: synergistic interactions of wear and corrosion. J Biomed Mater Res B 100B(6):1662-1671. doi:10.1002/Jbm.B.32735

15. Diomidis N, Mischler S, More NS, Roy M (2012) Tribo-electrochemical characterization of metallic biomaterials for total joint replacement. Acta Biomater 8(2):852-859. doi:10.1016/j. actbio.2011.09.034

16. de Souza GB, de Lima GG, Kuromoto NK, Soares P, Lepienski CM, Foerster CE, Mikowski A (2011) Tribo-mechanical characterization of rough, porous and bioactive $\mathrm{Ti}$ anodic layers. J Mech Behav Biomed Mater 4(5):796-806. doi:10.1016/j. jmbbm.2010.09.012

17. Olmedo DG, Paparella ML, Brandizzi D, Cabrini RL (2010) Reactive lesions of peri-implant mucosa associated with titanium dental implants: a report of 2 cases. Int J Oral Maxillofac Surg 39(5):503-507. doi:10.1016/j.ijom.2009.11.007

18. Souza J, Barbosa S, Ariza E, Celis J-P, Rocha L (2012) Simultaneous degradation by corrosion and wear of titanium in artificial saliva containing fluorides. Wear 292:82-88

19. Souza J, Henriques M, Oliveira R, Teughels W, Celis J-P, Rocha L (2010) Do oral biofilms influence the wear and corrosion behavior of titanium? Biofouling 26(4):471-478

20. Souza JC, Barbosa SL, Ariza EA, Henriques M, Teughels W, Ponthiaux P, Celis J-P, Rocha LA (2015) How do titanium and Ti6Al4V corrode in fluoridated medium as found in the oral cavity? An in vitro study. Mater Sci Eng C 47:384-393

21. Barril S, Mischler S, Landolt D (2005) Electrochemical effects on the fretting corrosion behaviour of Ti6Al4V in $0.9 \%$ sodium chloride solution. Wear 259(1):282-291

22. Binon PP, McHugh MJ (1995) The effect of eliminating implant/abutment rotational misfit on screw joint stability. Int $\mathrm{J}$ Prosthodont 9(6):511-519

23. do Nascimento C, Barbosa RES, Issa JPM, Watanabe E, Ito IY, Albuquerque Junior RF (2008) Bacterial leakage along the implantabutment interface of premachined or cast components. Int J Oral Maxillofac Surg 37(2):177-180. doi:10.1016/j.ijom.2007.07.026

24. Saidin S, Abdul Kadir MR, Sulaiman E, Abu Kasim NH (2012) Effects of different implant-abutment connections on micromotion and stress distribution: Prediction of microgap formation. J Dent 40(6):467-474. doi:10.1016/j.jdent.2012.02.009

25. Broggini N, McManus L, Hermann J, Medina R, Oates $T$, Schenk R, Buser D, Mellonig J, Cochran D (2003) Persistent acute inflammation at the implant-abutment interface. J Dent Res 82(3):232-237

26. Gratton DG, Aquilino SA, Stanford CM (2001) Micromotion and dynamic fatigue properties of the dental implant-abutment interface. J Prosthet Dentist 85(1):47-52

27. Goodman SB (2007) Wear particles, periprosthetic osteolysis and the immune system. Biomaterials 28(34):5044-5048

28. Manaranche C, Hornberger H (2007) A proposal for the classification of dental alloys according to their resistance to corrosion. Dent Mater 23(11):1428-1437 
29. Wang JJ, Sanderson BJ, Wang H (2007) Cyto-and genotoxicity of ultrafine $\mathrm{TiO}_{2}$ particles in cultured human lymphoblastoid cells. Mutat Res Genet Toxicol Environ Mutagen 628(2):99-106

30. Faghihi S, Li D, Szpunar JA (2010) Tribocorrosion behaviour of nanostructured titanium substrates processed by high-pressure torsion. Nanotechnology 21(48):485703. doi:10.1088/09574484/21/48/485703

31. Cobelli N, Scharf B, Crisi GM, Hardin J, Santambrogio L (2011) Mediators of the inflammatory response to joint replacement devices. Nat Rev Rheumatol 7(10):600-608. doi:10.1038/ nrrheum.2011.128

32. Souza P, Palmqvist P, Lundgren I, Lie A, Costa-Neto C, Lundberg P, Lerner UH (2010) Stimulation of IL-6 cytokines in fibroblasts by toll-like receptors 2. J Dent Res 89(8):802-807

33. Le Guehennec L, Soueidan A, Layrolle P, Amouriq Y (2007) Surface treatments of titanium dental implants for rapid osseointegration. Dent Mater 23(7):844-854. doi:10.1016/j.den tal.2006.06.025

34. Tomisa AP, Launey ME, Lee JS, Mankani MH, Wegst UG, Saiz E (2011) Nanotechnology approaches to improve dental implants. Int J Oral Maxillofac Implants 26:25-44

35. Das K, Bose S, Bandyopadhyay A (2007) Surface modifications and cell-materials interactions with anodized Ti. Acta Biomater 3(4):573-585. doi:10.1016/j.actbio.2006.12.003

36. Le Guehennec L, Lopez-Heredia MA, Enkel B, Weiss P, Amouriq Y, Layrolle P (2008) Osteoblastic cell behaviour on different titanium implant surfaces. Acta Biomater 4(3):535543. doi:10.1016/j.actbio.2007.12.002

37. Novaes AB Jr, de Souza SL, de Barros RR, Pereira KK, Iezzi G, Piattelli A (2010) Influence of implant surfaces on osseointegration. Braz Dent J 21(6):471-481

38. Cheng Z, Zhang F, He F, Zhang L, Guo C, Zhao S, Yang G (2010) Osseointegration of titanium implants with a roughened surface containing hydride ion in a rabbit model. Oral Surg Oral Med Oral Pathol Oral Radiol Endod 110(1):e5-12. doi:10.1016/ j.tripleo.2010.03.012

39. Anselme K (2000) Osteoblast adhesion on biomaterials. Biomaterials 21(7):667-681. doi:10.1016/s0142-9612(99)00242-2

40. Jayaraman M, Meyer U, Bühner M, Joos U, Wiesmann H-P (2004) Influence of titanium surfaces on attachment of osteoblast-like cells in vitro. Biomaterials 25(4):625-631. doi:10. 1016/s0142-9612(03)00571-4

41. Zhu X, Chen J, Scheideler L, Reichl R, Geis-Gerstorfer J (2004) Effects of topography and composition of titanium surface oxides on osteoblast responses. Biomaterials 25(18):4087-4103. doi:10.1016/j.biomaterials.2003.11.011

42. Monsees TK, Barth K, Tippelt S, Heidel K, Gorbunov A, Pompe W, Funk RH (2005) Effects of different titanium alloys and nanosize surface patterning on adhesion, differentiation, and orientation of osteoblast-like cells. Cells Tissues Organs 180 (2):81-95. doi:10.1159/000086749

43. Vangolu Y, Arslan E, Totik Y, Demirci E, Alsaran A (2010) Optimization of the coating parameters for micro-arc oxidation of Cp-Ti. Surf Coat Technol 205(6):1764-1773. doi:10.1016/j. surfcoat.2010.08.042

44. Ravanetti F, Borghetti P, De Angelis E, Chiesa R, Martini FM, Gabbi C, Cacchioli A (2010) In vitro cellular response and in vivo primary osteointegration of electrochemically modified titanium. Acta Biomater 6(3):1014-1024. doi:10.1016/j.actbio. 2009.09.022

45. Yang W-E, Hsu M-L, Lin M-C, Chen Z-H, Chen L-K, Huang $\mathrm{H}-\mathrm{H}$ (2009) Nano/submicron-scale $\mathrm{TiO}_{2}$ network on titanium surface for dental implant application. J Alloy Compd 479(12):642-647. doi:10.1016/j.jallcom.2009.01.021

46. Li L-H, Kong Y-M, Kim H-W, Kim Y-W, Kim H-E, Heo S-J, Koak J-Y (2004) Improved biological performance of $\mathrm{Ti}$ implants due to surface modification by micro-arc oxidation. Biomaterials 25(14):2867-2875. doi:10.1016/j.biomaterials. 2003.09.048

47. Matykina E, Arrabal R, Skeldon P, Thompson GE (2009) Transmission electron microscopy of coatings formed by plasma electrolytic oxidation of titanium. Acta Biomater 5(4):13561366. doi:10.1016/j.actbio.2008.10.007

48. Mendonça G, Mendonça DB, Aragao FJ, Cooper LF (2008) Advancing dental implant surface technology-from micron-to nanotopography. Biomaterials 29(28):3822-3835

49. Liu X, Chu PK, Ding C (2004) Surface modification of titanium, titanium alloys, and related materials for biomedical applications. Mater Sci Eng R 47(3):49-121

50. Alla RK, Ginjupalli K, Upadhya N, Shammas M, Ravi RK, Sekhar R (2011) Surface roughness of implants: a review. Trends Biomater Artific Organs 25(3):112-118

51. Montazeri M, Dehghanian C, Shokouhfar M, Baradaran A (2011) Investigation of the voltage and time effects on the formation of hydroxyapatite-containing titania prepared by plasma electrolytic oxidation on Ti-6Al-4V alloy and its corrosion behavior. Appl Surf Sci 257(16):7268-7275. doi:10.1016/j. apsusc.2011.03.103

52. Shokouhfar M, Dehghanian C, Montazeri M, Baradaran A (2012) Preparation of ceramic coating on Ti substrate by plasma electrolytic oxidation in different electrolytes and evaluation of its corrosion resistance: Part II. Appl Surf Sci 258(7):24162423. doi:10.1016/j.apsusc.2011.10.064

53. Matthews A, Leyland A, Yerokhin A, Pilkington T (2004) Novel plasma electrolytic treatment processes to improve the wear and corrosion performance of light-alloys. University of Sheffield, Department of Engineering Materials

54. Dzhurinskiy D, Gao Y, Yeung WK, Strumban E, Leshchinsky V, Chu PJ, Matthews A, Yerokhin A, Maev RG (2015) Characterization and corrosion evaluation of $\mathrm{TiO}_{2}$ :n-HA coatings on titanium alloy formed by plasma electrolytic oxidation. Surf Coat Technol. doi:10.1016/j.surfcoat.2015.01.022

55. Kuromoto NK, Simão RA, Soares GA (2007) Titanium oxide films produced on commercially pure titanium by anodic oxidation with different voltages. Mater Charact 58(2):114-121. doi:10.1016/j.matchar.2006.03.020

56. Cheng S, Wei D, Zhou Y, Guo H (2011) Characterization and properties of microarc oxidized coatings containing $\mathrm{Si}, \mathrm{Ca}$ and $\mathrm{Na}$ on titanium. Ceram Int 37(6):1761-1768. doi:10.1016/j.cer amint.2011.03.006

57. Shin KR, Kim YS, Yang HW, Ko YG, Shin DH (2014) In vitro biological response to the oxide layer in pure titanium formed at different current densities by plasma electrolytic oxidation. Appl Surf Sci 314:221-227. doi:10.1016/j.apsusc.2014.06.121

58. Oliveira FG, Ribeiro AR, Perez G, Archanjo BS, Gouvea CP, Araújo JR, Campos APC, Kuznetsov A, Almeida CM, Maru MM, Achete CA, Ponthiaux P, Celis J-P, Rocha LA (2015) Understanding growth mechanisms and tribocorrosion behaviour of porous $\mathrm{TiO}_{2}$ anodic films containing calcium, phosphorous and magnesium. Appl Surf Sci. doi:10.1016/j. apsusc.2015.02.163

59. Alves SA, Bayón R, Igartua A, Saénz de Viteri V, Rocha LA (2014) Tribocorrosion behaviour of anodic titanium oxide films produced by plasma electrolytic oxidation for dental implants. Lubr Sci 26(7-8):500-513. doi:10.1002/1s.1234

60. Fusayama T, Katayori T, Nomoto S (1963) Corrosion of gold and amalgam placed in contact with each other. J Dent Res 42:1183-1197

61. Alves A, Oliveira F, Wenger F, Ponthiaux P, Celis J-P, Rocha L (2013) Tribocorrosion behaviour of anodic treated titanium surfaces intended for dental implants. J Phys D 46(40): 404001 
62. Alves S, Bayón R, Igartua A, Saénz de Viteri V, Rocha L (2014) Tribocorrosion behaviour of anodic titanium oxide films produced by plasma electrolytic oxidation for dental implants. Lubr Sci 26(7-8):500-513

63. Oliveira FG, Ribeiro AR, Perez G, Archanjo BS, Gouvea CP, Araújo JR, Campos AP, Kuznetsov A, Almeida CM, Maru MM (2015) Understanding growth mechanisms and tribocorrosion behaviour of porous $\mathrm{TiO}_{2}$ anodic films containing calcium, phosphorous and magnesium. Appl Surf Sci 341:1-12

64. Holland R (1992) Corrosion testing by potentiodynamic polarization in various electrolytes. Dent Mater 8(4):241-245

65. Alexa Fluor ${ }^{\circledR} 488$ Phalloidin. http://products.invitrogen.com/ ivgn/product/A12379. Accessed 20 Jan 2015

66. Propidium Iodide. http://www.kpl.com/catalog/productdetail. cfm?Catalog_ID $=1 \&$ Category_ID $=170 \&$ Product_ID $=1021$. Accessed 20 Jan 2015

67. Shin KR, Ko YG, Shin DH (2011) Effect of electrolyte on surface properties of pure titanium coated by plasma electrolytic oxidation. J Alloys Compd 509(Suppl 1):S478-S481. doi:10. 1016/j.jallcom.2011.02.056

68. He J, Zhou W, Zhou X, Zhong X, Zhang X, Wan P, Zhu B, Chen W (2008) The anatase phase of nanotopography titania plays an important role on osteoblast cell morphology and proliferation. J Mater Sci 19(11):3465-3472. doi:10.1007/s10856-008-3505-3

69. Sul Y-T, Johansson CB, Petronis S, Krozer A, Jeong Y, Wennerberg A, Albrektsson T (2002) Characteristics of the surface oxides on turned and electrochemically oxidized pure titanium implants up to dielectric breakdown: the oxide thickness, micropore configurations, surface roughness, crystal structure and chemical composition. Biomaterials 23(2):491-501. doi:10. 1016/s0142-9612(01)00131-4

70. Cheng S, Wei D, Zhou Y (2012) The effect of oxidation time on the micro-arc titanium dioxide surface coating containing $\mathrm{Si}, \mathrm{Ca}$ and Na. Procedia Eng 27:713-717. doi:10.1016/j.proeng.2011. 12.510

71. X-q Wu, Xie F-q Hu, Z-c Wang L (2010) Effects of additives on corrosion and wear resistance of micro-arc oxidation coatings on TiAl alloy. Trans Nonferr Met Soc China 20(6):1032-1036. doi:10.1016/s1003-6326(09)60253-3

72. X-1 Shi, Q-1 Wang, F-s Wang, S-r Ge (2009) Effects of electrolytic concentration on properties of micro-arc film on Ti6Al4V alloy. Mining Sci Technol 19(2):220-224. doi:10. 1016/s1674-5264(09)60042-9

73. Park IS, Woo TG, Jeon WY, Park HH, Lee MH, Bae TS, Seol KW (2007) Surface characteristics of titanium anodized in the four different types of electrolyte. Electrochim Acta 53(2):863870. doi:10.1016/j.electacta.2007.07.067

74. Venkateswarlu K, Rameshbabu N, Sreekanth D, Bose AC, Muthupandi V, Subramanian S (2013) Fabrication and characterization of micro-arc oxidized fluoride containing titania films on Cp Ti. Ceram Int 39(1):801-812. doi:10.1016/j.ceramint. 2012.07.001

75. Cui X, Kim HM, Kawashita M, Wang L, Xiong T, Kokubo T, Nakamura T (2009) Preparation of bioactive titania films on titanium metal via anodic oxidation. Dent Mater 25(1):80-86. doi:10.1016/j.dental.2008.04.012

76. Frauchiger VM, Schlottig F, Gasser B, Textor M (2004) Anodic plasma-chemical treatment of $\mathrm{CP}$ titanium surfaces for biomedical applications. Biomaterials 25(4):593-606. doi:10. 1016/s0142-9612(03)00560-x

77. Manhabosco TM, Tamborim SM, dos Santos CB, Müller IL (2011) Tribological, electrochemical and tribo-electrochemical characterization of bare and nitrided Ti6Al4V in simulated body fluid solution. Corros Sci 53(5):1786-1793. doi:10.1016/j. corsci.2011.01.057
78. Landolt D, Mischler S, Stemp M, Barril S (2004) Third body effects and material fluxes in tribocorrosion systems involving a sliding contact. Wear 256(5):517-524. doi:10.1016/s0043-1648 (03)00561-1

79. Wheeler JM, Collier CA, Paillard JM, Curran JA (2010) Evaluation of micromechanical behaviour of plasma electrolytic oxidation (PEO) coatings on Ti-6Al-4V. Surf Coat Technol 204 (21-22):3399-3409. doi:10.1016/j.surfcoat.2010.04.006

80. Oh S, Daraio C, Chen L-H, Pisanic TR, Fiñones RR, Jin S (2006) Significantly accelerated osteoblast cell growth on aligned $\mathrm{TiO}_{2}$ nanotubes. J Biomed Mater Res Part A 78A(1):97103. doi:10.1002/jbm.a.30722

81. Vallés G, González-Melendi P, Saldaña L, Rodriguez M, Munuera L, Vilaboa N (2008) Rutile and titanium particles differentially affect the production of osteoblastic local factors. J Biomed Mater Res Part A 84A(2):324-336. doi:10.1002/jbm. a. 31315

82. Mints D, Elias C, Funkenbusch P, Meirelles L (2013) Integrity of implant surface modifications after insertion. Int $\mathrm{J}$ Oral Maxillofac Implants 29(1):97-104

83. Patel S, Solitro GF, Sukotjo C, Takoudis C, Mathew MT, Amirouche F, Shokuhfar T (2015) Nanotopography and surface stress analysis of Ti6Al4V bioimplant: an alternative design for stability. JOM 1-16

84. Runa M, Mathew M, Fernandes M, Rocha L (2015) First insight on the impact of an osteoblastic layer on the bio-tribocorrosion performance of Ti6Al4V hip implants. Acta Biomater 12:341351

85. Zywitzki O, Modes T, Sahm H, Frach P, Goedicke K, Glöß D (2004) Structure and properties of crystalline titanium oxide layers deposited by reactive pulse magnetron sputtering. Surf Coat Technol 180-181:538-543. doi:10.1016/j.surfcoat.2003. 10.115

86. Modes T, Scheffel B, Metzner C, Zywitzki O, Reinhold E (2005) Structure and properties of titanium oxide layers deposited by reactive plasma activated electron beam evaporation. Surf Coat Technol 200(1):306-309

87. Kaczmarek D, Domaradzki J, Wojcieszak D, Prociow E, Mazur M, Placido F, Lapp S (2012) Hardness of nanocrystalline $\mathrm{TiO}_{2}$ Thin Films. In: Journal of Nano Research, 2012. Trans Tech Publication, pp 195-200

88. Zysset PK, Guo XE, Hoffler CE, Moore KE, Goldstein SA (1999) Elastic modulus and hardness of cortical and trabecular bone lamellae measured by nanoindentation in the human femur. J Biomech 32(10):1005-1012

89. FANUSCU M (2003) Elastic Modulus and Hardness of Cortical and Cancellous Bone Measured by Nanoindentation in Maxilla and Mandible. In: 32nd Annual Meeting and Exhibition of the AADR

90. Zhang W, Du K, Yan C, Wang F (2008) Preparation and characterization of a novel $\mathrm{Si}$-incorporated ceramic film on pure titanium by plasma electrolytic oxidation. Appl Surf Sci 254 (16):5216-5223. doi:10.1016/j.apsusc.2008.02.047

91. Bigerelle M, Anselme K, Noël B, Ruderman I, Hardouin P, Iost A (2002) Improvement in the morphology of Ti-based surfaces: a new process to increase in vitro human osteoblast response. Biomaterials 23(7):1563-1577. doi:10.1016/s0142-9612(01) 00271-x

92. Park S-J, Bae S-B, Kim S-K, Eom T-G, Song S-I (2011) Effect of implant surface microtopography by hydroxyapatite gritblasting on adhesion, proliferation, and differentiation of osteoblast-like cell line, MG-63. J Korean Assoc Oral Maxillofac Surg 37:214-224

93. Alberts B, Johnson A, Lewis J, Raff M, Roberts K, Walter P (2002) The cytoskeleton. In: Alberts B, Johnson A, Lewis J, 
Raff M, Roberts K, Walter P (eds) Molecular biology of the cell, 4th edn. Garland Science, New York, pp 907-982

94. Stamenovic D (2005) Effects of cytoskeletal prestress on cell rheological behavior. Acta Biomater 1(3):255-262. doi:10.1016/ j.actbio.2005.01.004

95. Titushkin I, Cho M (2007) Modulation of cellular mechanics during osteogenic differentiation of human mesenchymal stem cells. Biophys J 93(10):3693-3702. doi:10.1529/biophysj.107. 107797

96. Takahashi S, Abe T, Gotoh J, Fukuuchi Y (2002) Substratedependence of reduction of MTT: a tetrazolium dye differs in cultured astroglia and neurons. Neurochem Int 40(5):441-448

97. Korkusuz P, Korkusuz F (2004) Hard tissue-biomaterial interactions. In: Yaszemski MJ, Trantolo DJ, Lewandrowski K,
Hasirci V, Altobelli DE, Wise DL (eds) Biomaterials in orthopedics. Taylor and Francis, New York, pp 1-49

98. Ma CF, Li DM, Li HJ, Jiang BL, Zhang LJ (2005) Modification of titanium surface with calcium and phosphorus ions using micro-arc oxidation and its effect on osteoblast attachment. Di Yi Jun Yi Da Xue Xue Bao 25(1):62-65

99. Brammer KS, Oh S, Cobb CJ, Bjursten LM, Hvd Heyde, Jin S (2009) Improved bone-forming functionality on diameter-controlled $\mathrm{TiO}_{2}$ nanotube surface. Acta Biomater 5(8):3215-3223. doi:10.1016/j.actbio.2009.05.008

100. Wang S, Liu Y, Zhang C, Liao Z, Liu W (2014) The improvement of wettability, biotribological behavior and corrosion resistance of titanium alloy pretreated by thermal oxidation. Tribol Int 79:174-182. doi:10.1016/j.triboint.2014.06.008 